\title{
Assessing sex differentials in under-five mortality in sub-Saharan Africa: A cross-national comparative analysis
}

\author{
Adébiyi Germain Boco*
}

\begin{abstract}
This paper investigates and compares country-specific sex differentials in childhood mortality in thirty sub-Saharan African countries. Data from the Demographic and Health Surveys (DHS) were analyzed to assess sex differentials in U5M rates before and after adjustment for individual, household, and community-level factors, using multilevel discrete-time hazard models. The findings show a systematically higher mortality for male children compared to female in all countries except Sierra Leone and Swaziland. The relationship is significant in nineteen of the thirty countries. Across the region, males have 17-54 per cent higher odds of dying before age five. These patterns remained when controls were added for individual and community-level factors, as well as unobserved community-level effects.
\end{abstract}

Keywords: Sex differences, mortality, hazard analysis, cross-national comparison, sub-Saharan Africa.

\section{Résumé}

Cet article examine et compare les différentiels de la mortalité des enfants selon le sexe dans 30 pays d'Afrique au sud du Sahara. Les données nationales des dernières Enquêtes Démographiques et de Santé ont été analysées au moyen des modèles multi-niveaux de régression logistique de survie en temps discret pour estimer le risque relatif de la mortalité infanto-juvénile selon le sexe, avant et après contrôle des facteurs individuels et communautaires. Les résultats indiquent une surmortalité masculine dans la quasi-totalité des pays, sauf au Sierra Leone et au Swaziland. Les garçons de moins de cinq ans présentent un risque de décès de $17 \%-54 \%$ plus élevé, comparés aux filles de même âge. Les résultats sont robustes des facteurs de control mesurés au niveau individuel et communautaire, aussi bien pour l'hétérogénéité inobservée.

Mots-clés : Mortalité différentielle selon le sexe, analyse de survie, comparaison transnationale, Afrique subsaharienne.

\section{Introduction}

In sub-Saharan Africa (SSA), disparities in childhood mortality have been consistently reported, with males bearing an excess risk of dying before age five (United Nations 2011; Sawyer 2012; Wang et al. 2012). The latest annual report of the United Nations Inter-agency Group for Child Mortality Estimation (UN IGME) shows that on average in 2012, 103 boys under five die for each 1,000 live births, compared with only 92 girls (UN IGME 2013: 27). The basic research question posed here is

* Prentice Institute for Global Population \& Economy, University of Lethbridge, 4401 University Drive West, Lethbridge AB Canada T1K 3M4. Email: germain.boco@uleth.ca. 
what factors explain the sex differentials in childhood mortality? The challenge of sex-based disparities in childhood mortality remains one of the greatest public health research challenges and is of special importance for policies and programs targeting children's well-being and survival in SSA, the region with the highest childhood mortality in the world (Whitehead 1992; LeGrand 2000; Ashorn et al. 2002; United Nations 2011).

Sex differences in childhood mortality have been the subject of extensive investigation over the past two decades in less developed countries (LDC) — especially in Asia, where son preference often results in daughter neglect (Miller 1981; Kishor 1993; Hill and Upchurch 1995; Ren 1995; Filmer et al. 1998; Pollard and Hyatt 1999; Yount 2001; Arokiasamy 2004; Li et al. 2004; Sawyer 2012; Monden and Smits 2013; Pham et al. 2013; Rosenstock et al. 2013). The issue has not as often been addressed in SSA (Desgrées du Loû et al. 1995; LeGrand and Mbacké 1995; Tabutin et al. 2001; Ashorn et al. 2002; Garenne 2003; Aaby et al. 2007; Pongou 2013). Most research examining sex differences in childhood mortality has noted increased frailty among male infants, although that is mitigated as male children grow older (Pollard and Hyatt 1999; Kalben 2000; DeWitte 2010; Handa et al. 2010; United Nations 2011; Pongou 2013). Some previous research suggests that sex differentials in the mortality of young children result from a complex interplay of biological/genetic and social/environmental factors that impact mortality at different stages in the life course (Biaye 1994; Trovato and Lalu 1996; Waldron 1998; Kalben 2000; Luy 2003; Vallin 2006; Drevenstedt et al. 2008; Rogers et al. 2010; United Nations 2011; Pongou 2013).

Although the association between the sex of the child and risk of death has been examined, the mechanisms by which sex uniquely influences childhood mortality are not well understood or empirically documented. A major limitation of previous studies examining sex differences in childhood mortality is lack of adequate controls for other relevant biological, social, and environmental factors (see Garenne 2003; United Nations 2011). Analysis of mortality differentials requires examining the interactions of characteristics influencing mortality. Controlling potential confounding variables in the analytic models is needed to identify the relative effects of child's sex net of the effects of other variables (Mishra et al. 2004; Monden and Smits 2013; Pongou 2013; Rosenstock et al. 2013). In addition, most prior research has relied on either individual-level explanations or ecological approaches to the determinants of gender inequality in childhood mortality (e.g., Hill and Upchurch 1995; Garenne 2003; Fuse and Crenshaw 2006; Aaby et al. 2007). Such studies have often not accounted for individual, household, or community-level factors in tandem. This limitation can be addressed with a multilevel design that integrates individual and group-level data (Monden and Smits 2013). Multilevel modeling is an effective strategy for assessing compositional (individual characteristics) and contextual (area or group properties) effects on health (Duncan et al. 1998; Diez Roux 2003). It is now well established that the development of multilevel modeling techniques has created a mechanism for measuring the influence of community factors and unobserved community effects on health outcomes, while providing a robust method for analyzing hierarchically clustered data (Stephenson et al. 2006: 84; Goldstein 2010).

A few multinational studies of sex differentials in childhood mortality in sub-Saharan Africa have done multivariate analysis, particularly using a comparative perspective. Pongou tested the "pre-conception origins hypothesis" to explain the excess infant mortality $(<1$ year) of boys with respect to girls by decomposing the sex differences in infant mortality into the effects of the pre-conception environment (e.g. parental exposure to chemicals, parental illnesses) and child biology (Pongou 2013). Using pooled data from the Demographic and Health Surveys (DHS) collected in 31 sub-Saharan African countries (between 1986 and 2005) to compare sex differences in infant mortality across 
singletons, all twins, same-sex twins, and opposite-sex twins, Pongou found that both pre-conception environment and child biology increase the mortality among male infants, but the effect of biology is substantially smaller than the literature suggests (Pongou 2013). Monden and Smits (2013), too, have analyzed the DHS data to find that increasing maternal education is associated with reduced female disadvantages in U5M in sub-Saharan Africa and southern Asia. However, Pongou (2013), and Monden and Smits (2013) indicate a regional pattern in sex differences in childhood mortality based on the pooled coefficients of sex differences in infant and child mortality from multiple countries. This approach may mask significant disparities among countries (Rousham 1999:50; Garenne 2003:601). Thus, the consistency of findings across countries over different periods needs to be examined. Under a cross-national comparative perspective, this study is thus able to highlight the heterogeneity in sex differentials in childhood mortality. In particular, this paper provides a detailed multi-country, multivariate analysis of the patterns of country-specific sex differences in childhood mortality in SSA. Gaps by sex in childhood mortality vary cross-nationally, suggesting that differences are affected by country-specific conditions (UN IGME 2013). Due to their different historical, cultural, economic, and political situations, SSA countries form an important source of variation in attitudes, preferences, and practices in the domains of reproductive and population health and related policies. To date, there has been limited research exploring the effect of these contexts on sex differences in childhood mortality.

The present study expands on previous work by systematically testing a variety of factors, including biological indicators of health, attitudes toward gender preference, and household and community level socio-economic and environmental factors. In order to build a multi-country understanding of sex differentials in childhood in SSA, this paper seeks to investigate and compare the male-tofemale ratios in under-five mortality (U5M) in thirty countries that have Demographic and Health Surveys (DHS). Especially, data from the latest surveys were analyzed to assess country-specific sex differentials in U5M rates before and after adjustment for measures of individual- and communitylevel factors, using a multilevel discrete-time hazard model.

\section{Theoretical framework and hypothesis}

Despite the fact that sex gaps in mortality have been observed, explanatory models and theories that account for them vary widely. Two major theoretical perspectives emerge in the literature on the determinants of sex differences in childhood mortality (Waldron 1983; Hazzard 1986; Hill and Upchurch 1995; Pollard and Hyatt 1999; Kalben 2000; Wells 2000; Rieker and Bird 2005; Fuse and Crenshaw 2006; Vallin 2006; Pongou 2013; Rosenstock et al. 2013). The first is the biological advantage/ disadvantage theory and the second is the environmental mechanisms approach.

The biological advantage/disadvantage perspective maintains that excess mortality of male children is due to their weaker biological makeup (Pongou 2013: 436). Crediting the work of Waldron (1998) and United Nations (2011), Sawyer (2012: 2) claims that "newborn girls have a biological advantage in survival over newborn boys, with lesser vulnerability to perinatal conditions (including birth trauma, intrauterine hypoxia and birth asphyxia, prematurity, respiratory distress syndrome, and neonatal tetanus), congenital anomalies, and such infectious diseases as intestinal infections and lower respiratory infections." However, some studies note that the strong effect of biological factors in early infancy ( $<1$ year) is alleviated in childhood (1-4 years) (Garenne and Lafon 1998; United Nations 2011; Sawyer 2012). Waldron (1987), in investigating overall neonatal mortality rates by sex in developing countries, suggests that biological factors may be more important in the early neonatal period, and environment may play a larger role in the late neonatal period. In general, biological fac- 
tors refer to immutable factors specific to both the newborn and parents (Masuy-Stroobant 2006; Rosenstock et al. 2013). These include maternal age, parity, gestational age, birth weight, twin status, and genetic factors (Masuy-Stroobant 2006). However, in recent work, Pongou (2013) suggests a hypothesis that distinguishes between the effects of pre-conception or prenatal environment and child biology on sex differences in infant mortality. The pre-conception environment involves factors that are external to a child and that occur around the time of conception. These factors might be pure environmental hazards (such as parental exposure to chemicals) or medical factors (such as parental illnesses).

The environmental mechanisms approach focuses on mutable external factors that impact morbidity and mortality in the first five years of life (Rosenstock et al. 2013). Examples include maternal and newborn nutrition, sex preference, newborn care practices, breastfeeding practices, care-seeking behaviour, household environmental health hazards, and household- and community-level socioeconomic factors (Rosenstock et al. 2013). A number of previous studies have observed the roles of maternal and neonatal care, breastfeeding, appropriate complementary feeding, and quality of drinking water and sanitation in the continuum from child birth to child survival (Rousham 1999; Caulfield et al. 2004; Bhutta et al. 2008; Debes et al. 2013). In addition, it is now generally accepted that the physical and social environment, and other neighbourhood characteristics, can have a significant effect on life chances over and above the effect of their individual characteristics (Bernard et al. 2007; van Ham et al. 2012). Studies have found that community-level factors such as antenatal care coverage (percentage of mothers receiving antenatal care by trained health personnel), availability of basic infrastructure, average education of women in the community, and family structures are associated with infant and child mortality in LDCs (Sastry 1996; Kravdal 2004; Boyle et al. 2006; Chen et al. 2007; Omariba and Boyle 2007; Van de Poel et al. 2009). Empirical research has shown that neighbourhood poverty reduces the likelihood of safe delivery in several countries in SSA (Stephenson et al. 2006; Gage 2007). As noted, the determinants of childhood mortality may lie at different levels, i.e., macro, meso, and micro.

Mosley and Chen (1984) propose a comprehensive analytical framework for the study of child survival determinants in LDCs that has been used widely (Hill 2003). The framework combines sociological and biological explanatory models in a single conceptual framework by sorting independent variables as distal socio-economic determinants, followed by proximate determinants, creating an analytical hierarchy (Malqvist et al. 2012). Mosley and Chen (1984) include among the socioeconomic determinants community-, household-, and individual-level characteristics. In this theoretical framework, social and economic determinants of infant and child survival operate through a common set of biological mechanisms or proximate determinants which are categorized as follows: (1) maternal factors (age, parity, birth interval); (2) environmental factors (air, water, food, etc); (3) nutrient supply (calories, proteins and micronutrients); (4) injury; and (5) personal illness control (preventive and curative; Mosley and Chen 1984: 27). Most of these variables have been found to be associated with infant and child mortality in LDCs (see Madise et al. 2003; Boyle et al. 2006; Van de Poel et al. 2009; Singh et al. 2012).

In this paper, the analytical model draws on the Mosley-Chen framework to examine the determinants of sex differences in under-five mortality rates. Sex at birth is considered a proximate factor, and refers to the permanent and immutable biological characteristics common to individuals in all societies and cultures (Pollard and Hyatt 1999; FAO 2001). By integrating the biological and environmental perspectives on sex differences in early age mortality in human populations, this paper seeks to test whether individual or community-level factors explain sex disparities in the mortality of children aged 0 to 5 across SSA. 


\section{Data source and sample}

This analysis relies on the Demographic and Health Surveys (DHS) from thirty countries in subSaharan Africa surveyed between 2004 and 2012 (Table 1). The DHS are nationally representative household surveys that provide detailed information on child mortality, health, and fertility (Hancioglu and Arnold 2013). The surveys are led by ICF International /MEASURE DHS, in collaboration with local institutions (DHS n.d.). In each survey, a two-stage probabilistic sampling design is used to select clusters or census enumerations areas (EAs) at the first stage and households at the second stage. All sub-Saharan African countries with a standard DHS after the year 2000 are eligible for inclusion in this analysis. For each country, data from the latest available survey at the time of the study are used (Table 1). The analyses are limited to more recent surveys to have the same control variables available across all datasets.

DHS uses a standardised questionnaire to facilitate between-country comparisons. The Individual Questionnaire for eligible women aged 15-49 includes a complete birth history (DHS 2012). Full birth histories are the primary material collected through the DHS since 1984, and the quality is generally acknowledged to be as among the best for data on births and infant and child deaths in resource-limited settings (Arnold 1990: 83-111; Pullum 2008), and comparable in accuracy to prospectively gathered data (Garenne and van Ginneken 1994; Byass et al. 2007). Typically, information is collected on the date of birth of each child, whether the child is still alive, and, if the child has died, the age at death (Rutstein 2008; Hill et al. 2012). The DHS surveys also include questions on women's basic socio-demographic characteristics, household ownership, and antenatal and delivery care, thus offering a rich source of information to study childhood mortality (Madise et al. 2003; Van de Poel et al. 2009; Pamuk et al. 2011). In addition, the DHS incorporates questions about child gender preferences since 1992, and is currently the only data source for conducting a cross-national comparison of attitudinal measures of child gender preference in sub-Saharan African countries (Fuse 2010).

In this study, the sample includes all singleton births occurring to women in the five years prior to the interview. Twins or other multiple birth children are excluded, due to possible survival issues associated with multiples (Guo and Grummer-Strawn 1993; Justesen and Kunst 2000; Heaton et al. 2005). In addition, limitation to only the most recent births allowed to include the healthcare access variables (e.g., the type of person who assisted with the delivery of the child, a key determinant of infant and child mortality) that are available only for births during the five years preceding the survey. Given these restrictions, the present analysis is based on 272,003 children (137,658 boys and 134,345 girls) born between 1998 and 2012. The number of children by country included ranges from 2,755 in Swaziland to 27,141 in Nigeria (Table 1).

\section{Variables and measurement}

The dependent variable in this study is the risk of under- 5 death (0-59 months), defined as the probability of dying between birth and the fifth birthday. U5M was estimated for the 5 years preceding the survey.

The independent variable of interest is the sex of the child, defined as a binary variable that equals 1 if male and 0 if female. A number of biological and environmental variables associated with U5M in the literature were included as control variables (Mosley and Chen 1984; Hobcraft et al. 1985; Sastry 1996; Van de Poel et al. 2009; Pamuk et al. 2011). In the multivariate models, it is estimated whether inclusion of these variables attenuates the association between the sex of child and the risk of mortality. Control variables are then categorized as either individual-level or community-level. 
Individual-level control variables include maternal attributes as well as the child's. Child variables include birth weight of child (large, very small, and smaller than average), "birth order" and "previous birth interval" combined to create a new variable with five categories (birth order one; birth order two or three, and birth interval less than or equal to 23 months; birth order two or three, and birth interval greater than 23 months; birth order four or greater, and birth interval less than or equal to 23 months; birth order four or greater, and birth interval greater than 23 months). Maternal covariates include mother's age at each birth (less than 20 years, 20-34 years, greater than 35 years), mother's education (no education, primary, secondary or higher), trained attendant at delivery (whether or not birth was attended by a doctor, a nurse or a midwife), and gender preference for children (no gender preference, balance preference, daughter preference, son preference). The latter variable is constructed from responses to three fertility preference questions, which are included in every survey. Women with living children were asked, "If you could go back to the time you did not have any children and could choose exactly the number of children to have in your whole life, how many would that be?" Women without living children were asked, "If you could choose exactly the number of children to have in your whole life, how many would that be?" Women were then asked, "How many of these children would you like to be boys, how many would you like to be girls, and for how many would the sex not matter?" (Fuse 2010: 1035). Studies show excess female child mortality in cultures with son preference, such as China, South Korea, Bangladesh, and India (Hill and Upchurch 1995; Larsen et al. 1998; United Nations 1998; Li et al. 2004). This increased risk of child mortality for girls is explained in terms of discrimination against girls, socioeconomically as well as through health-related behavioural factors (Yount 2001; Arokiasamy 2004; Li et al. 2004). A number of studies report that parents' beliefs about gender roles are a key determinant to their involvement in the child's health and healthcare (see Garfield and Isacco Iii 2012; Zvara et al. 2013). Gender ideologies represent what are seen as appropriate roles for men and women, and these beliefs affect behaviours (McHale and Huston 1984; Zvara et al. 2013). In sub-Saharan Africa, gender-based social inequality is a structural force that may condition the association between the sex of newborns and the risk of mortality (Wamani et al. 2007; Dodoo and Frost 2008).

Household-level variables include socio-economic status, measured by a household wealth quintile. Household wealth is captured in DHS through a composite index for relative standard of living derived from country-specific indicators of asset ownership, housing characteristics and water and sanitation facilities (Houweling et al. 2003; Rutstein and Kiersten 2004).

Community-level variables included here are place of residence (urban/rural areas), the community's socioeconomic status (mean wealth index quintile score, categorized as low or high); proportion of women in the community with secondary or higher education, proportion of births delivered in health facilities, and an index measuring the extent of son preference (the proportion of women who reported a son as the type of gender preference). These variables are constructed by aggregating individual-level and household-level characteristics at the cluster level (i.e., the primary sampling units, PSU) for the DHS. The DHS surveys use a stratified cluster sample design. Within each province, a number of PSUs are selected. These units typically encompass one or a few villages, or part of a town (Hancioglu and Arnold 2013). On average, about 25 households are randomly selected in each primary sampling unit, and women of reproductive age in the household are interviewed (Aliaga and Ren 2006; ICF International 2012). The average number of children per cluster in this sample ranges from 7.0 (range 1-28, SD 0.20) in Ghana to 30.2 (range 6-67, SD 12.0) in Senegal (Appendix Table 1). Appendix Table 2 shows the operationalization of independent variables used in this study. 
Boco: Assessing sex differentials in under-five mortality in sub-Saharan Africa

\section{Analytical model}

A multilevel discrete-time hazard model, that is, a combination of discrete-time hazard model (i.e., an analytic technique that deals correctly with right-censoring) and multilevel modeling (i.e., an analytic technique that considers the clustering of children into communities) is employed in this study (Allison 1982; Kuate-Defo 2001; Sear et al. 2002; Snijders and Bosker 2012). The outcome variable is children's risk of mortality at any time between birth and 59 months of age or between birth and the survey date for children who had not yet reached age five at time of interview. Children who were still alive at the interview date were right-censored. Since in the DHS age at death (reported in days and months) is subject to heaping at certain ages, a discrete formulation of time is preferred to a continuous one (Gyimah 2009). Discrete-time hazard models require that episodes be split into periods of risk (Singer and Willett 2003). Three exposure periods are defined here: the first month of life (age 0 months), months 1-11, and months 12-59. These intervals cover the components of the $\mathrm{U} 5 \mathrm{M}$, and are based on excepted categorization into neonatal mortality (in the first month), postneonatal mortality (months 1-11), and child mortality (months 12-59), respectively (Ren 1995; Bicego and Ahmad 1996; Sear et al. 2002:48; Hill and Choi 2006; Rajaratnam et al. 2010).

Relying on standard discrete-time hazard techniques, however, ignores the fact that children are clustered in families/communities. Previous studies in LDCs have shown that mortality risks are clustered in that even after controlling for community and household characteristics, mortality risks differ systematically across communities or households (Das Gupta 1997; Sear et al. 2002; Heaton et al. 2005; Campbell and Lee 2009; Van de Poel et al. 2009; Saha and van Soest 2011; Edvinsson and Janssens 2012; Van Bodegom et al. 2012).

The primary motivation for a multilevel analysis stems from the hierarchically clustered nature of the DHS data (Mazumdar 2012). Typically, children are nested into mothers, mothers are nested into households, households into PSUs, and PSUs into regions/provinces. Hence, factors affecting health outcomes in general, and child survival in particular, can arise from different levels of aggregation (Sastry 1996; Manda 1998; Bingenheimer and Raudenbush 2004; Omariba and Boyle 2007; Gyimah 2009; Corsi et al. 2011; Mazumdar 2012). Apart from individual bio-demographic and health attributes (such as age, sex, birth order, birth weight), which are independently determined for every child, siblings share certain common characteristics of the mother and the household (e.g., mother's education and household economic status), and children from a particular community have in common community factors such as availability of health facilities and outcomes (Mazumdar 2012). As a result, many scholars assert that unobserved heterogeneity in the outcome variable is also correlated at the cluster levels (see Manda 1998; Bingenheimer and Raudenbush 2004; Mazumdar 2012: 3). The use of multilevel modeling accommodates the hierarchical nature of the data, and corrects estimated standard errors to allow for clustering of observations within units (Goldstein 2010; Snijders and Bosker 2012).

Studies using fixed effects models to investigate determinants of child mortality and to control for unobservable variables at the cluster level lead to the difficulty that if the fixed effect is assumed away, then the effect of those variables that do not vary in a cluster will be lost in the process (Frankenberg 1995; Desai and Alva 1998; Campbell and Lee 2009). With such an approach, the effect of any variable that does not vary among children in the cluster (for example, urban/rural residence) cannot be estimated. Instead, the variance-component model corrects for the problem of correlated observations in a cluster, by introducing a random effect at each cluster (Snijders and Bosker 2012). In other words, subjects in the same cluster have a shared random intercept in the model. In this 
analysis, given that the number of children per mother and mother per household is very small, then children, mothers, and households are considered as part of a same level (level 1), as nested within communities (level 2). Thus, two-level random-effects discrete-time hazard models were fitted to assess sex differences in mortality among under-five children. The models had the following general specification (Wong and Mason 1985; Sear et al. 2002):

$$
\log \left[\left(\mathrm{p}_{\mathrm{tij}} /\left(1-\mathrm{p}_{\mathrm{tij}}\right)\right]=\alpha_{\mathrm{t}}+\mathrm{m} \mathbf{M}_{\mathrm{ij}}+\beta \mathbf{X}_{\mathrm{ij}}+\mu_{\mathrm{j}}\right.
$$

where $\mathrm{p}_{\mathrm{tij}}$ is the probability that child $\mathrm{i}$ in community $\mathrm{j}$ observed in the time interval $\mathrm{t}$ dies within that interval; $M_{i j}$ is a dummy variable indicating whether the sex at birth of child is male, $\mathrm{m}$ represents the vector of the coefficients associated with the sex of the child; $X_{\mathrm{ij}}$ represents a vector of individualand community-level explanatory variables; $\beta$ is a vector of regression parameters associated with $\mathrm{X}_{\mathrm{ij}} ; \alpha_{\mathrm{t}}$ is a function of time and denotes the effect of age on mortality; and $\mu_{\mathrm{j}}$ is the community-level random effect assumed to be normally distributed with mean equal to zero and variance $\sigma_{\mu}^{2}$.

The variance can also be interpreted in terms of intra-class correlation (ICC) in a latent variable, reflecting a number of unobserved factors that are shared among children from the same community. For the binary logit model, ICC is estimated as $\rho=\sigma_{\mu}{ }^{2} /\left(\sigma_{\mu}{ }^{2}+\pi^{2} / 3\right)$, where $\sigma_{\mu}^{2}$ is the estimated community-level variance and $\pi^{2} / 3$ (equal to 3.29) represents the variance of a standard logistic distribution (Snijders and Bosker 2012: 305). The fixed and random parameter estimates (along with their standard errors) for the multilevel binomial logit link model were estimated using the method of marginal quasi-likelihood (MQL) with a first-order Taylor series expansion, as implemented within the MLwiN (version 2.28, University of Bristol; Rasbash et al. 2012; Leckie and Charlton 2013). The results are shown as odds ratios (ORs) with 95 per cent confidence intervals (CIs). The sex differential in mortality is measured as the boy/girl ratio of the five-year probabilities of dying between birth and exact age five years. $\operatorname{Exp}\left(\beta_{k}\right)$ is the estimated ORs for those who are a unit apart on $X_{k}$, net of other predictors in the model. If the odds ratio for U5M is greater than one, it can be interpreted as $(\mathrm{OR}-1)^{*} 100 \%$ increased odds of dying before reaching the age of five. If the odds ratio is smaller than one, it can be interpreted as $(1 / \mathrm{OR}-1)^{*} 100 \%$ decreased odds of dying under age five. All analyses were conducted using Stata 12.1 and MLwiN (Leckie and Charlton 2013).

Following previous studies, a model-building strategy is employed that begins with the baseline model and progressively adds covariates for different sets of biological and environmental characteristics that are measured at the individual- and community-levels (e.g., Rogers et al. 2010; Bharadwaj and Lakdawala 2013). Four models are systematically estimated for each of the thirty countries studied. More specifically, I start with a baseline model that includes child sex and age (Model 1). The next model (Model 2) adds to the base model the individual-level control variables (child characteristics, maternal variables, and household wealth). Model 3 adds to Model 2 community-level variables, which include place of residence, community wealth index, level of mother's education in the community, level of facility delivery in the community, as well as index for the extent of son preference.

The focus of the analysis is change in the coefficient of the child's sex with the introduction of successive blocks of variables. Since the primary goal is to evaluate the effect of the child's sex on the risk of U5M, the approach here examines what this effect is before and after controlling for other factors, so as to determine whether such an effect is direct or mediated through other predictors (Baron and Kenny 1986; Moffitt 2005). If the coefficient for the sex variable is reduced by the addition of other variables, then part of the dynamic underlying the effect of the child's sex is presumed to be due to relationships between sex and other variables (see Rogers et al. 2010). 
Finally, Model 4 adds to Model 3 an interaction term between sex of the newborn and the child's age. The Wald test is run to compare whether the model with interaction terms as predictors fits significantly better than a model without interaction terms (Singer and Willett 2003). Because major causes of death differ substantially at different ages, the sex differential in childhood mortality may be quite different at different ages of children (Retherford et al. 1989; Forste 1994; Ren 1995; Manda 1999). To test whether the sex of the child has a differential impact on the risk of dying by age 5 by duration of exposure, a series of dichotomous control variables is included to capture the interaction between exposure to the risk of dying before age 5 ( $0-1$ months, 1-11 months, and 12-59 months) and the child's sex. Instead of running the hazard models generating estimates for three age intervals separately - the neonatal period (first month), post-neonatal period (exact ages, 1 to 12 months), and childhood period (exact ages, 12 to 60 months) — this analysis provides the odds of under-5 death within each discrete period, given that death has not already occurred. Furthermore, it is possible that at least some of the control variables interact with the child's sex, inasmuch as the effect of child's sex on mortality risk may vary by the category of a control variable (Mishra et al. 2004: 275). However, using a large sample of pooled DHS data from Sub-Saharan African countries, Pongou found that infant mortality ( $<1$ year) by sex is not affected by the interactions between biology and climate, or between biology and social status (e.g., maternal education), after controlling for the effects of unobserved pre-conception factors (Pongou 2013). Since the justification for including the control variables is to hold them constant in the models, Mishra et al. (2004: 1652) are followed, and no interactions between child's sex and the control variables are included.

\section{Results}

\section{Country profiles}

Table 1 presents the countries, survey years, number of clusters, and sample births included in the analysis. It also shows the U5M rate for the five-year period preceding the survey, sex ratio at birth, and the percentage of child males in the sample. The DHS sampling weights are used to produce nationally representative estimates. As expected, in most countries, more than half of children born are boys. The sex ratios at birth — number of male births divided by female births times 100_ show that in the samples, the number of boys born outnumbers girls born in most of the countries, ranging between 101 in Benin and 109 in Ethiopia. Exceptions to this pattern are found in Cameroon, Congo Democratic Republic, Congo (Brazzaville), Malawi, Sierra Leone, and Zambia. In these countries, the sex ratio is less than 100, indicating that there are more girls at birth. The lowest level of sex ratios at birth was recorded in Cameroon, with 96 male births per 100 female births (Table 1). Despite focusing the analysis on low-income countries in the SSA region, heterogeneity is observed in national U5M. Niger had the highest U5M, with 198 under-5 death deaths per thousand live births. The lowest U5M rate of 65 per thousand was found in Gabon.

\section{Comparability of data between sexes}

Appendix Table 2 compares the distribution of the selected characteristic for males and females for every country studied. Cross-tabulations and Pearson's chi-squared $\left(\chi^{2}\right)$ analyses are used to evaluate differences in the association between the sex and covariates. This table reveals remarkable differences in the distribution of the covariates by child's sex. In particular, differences between male and female children by child's birth weight are significant in all countries (Chi-square p-values $(\mathrm{p})<0.050)$ 
Table 1. Survey year, number of sample clusters and sample births, and selected characteristics ${ }^{1}$ for thirty sub-Saharan Africa countries.

\begin{tabular}{|c|c|c|c|c|c|c|}
\hline Country & $\begin{array}{c}\text { Survey } \\
\text { year }\end{array}$ & $\begin{array}{l}\text { Number } \\
\text { of sample } \\
\text { clusters }\end{array}$ & $\begin{array}{c}\text { Sample births } \\
\text { (all singleton } \\
\text { births in the five } \\
\text { years before the } \\
\text { survey) }\end{array}$ & $\begin{array}{l}\text { Sex ratio at birth } \\
\text { in the sample } \\
\text { (number of male } \\
\text { births divided } \\
\text { by female births } \\
\text { times 100) }\end{array}$ & $\begin{array}{l}\text { Percentage } \\
\text { of the } \\
\text { children } \\
\text { males in } \\
\text { sample }\end{array}$ & $\begin{array}{l}\text { U5M } \\
\text { rate (per } \\
1000 \text { live } \\
\text { births)* }\end{array}$ \\
\hline Benin & 2006 & 750 & 15033 & 101.4 & 50.3 & 125 \\
\hline Burkina Faso & 2010 & 573 & 14776 & 102.8 & 50.7 & 129 \\
\hline Burundi & 2010 & 376 & 7798 & 103.9 & 51.0 & 96 \\
\hline Cameroon & 2011 & 578 & 11251 & 96.4 & 49.1 & 122 \\
\hline Chad & 2004 & 196 & 5840 & 103.8 & 50.9 & 191 \\
\hline Congo (Brazzaville) & $2011-12$ & 384 & 7842 & 98.3 & 49.6 & 117 \\
\hline Congo Democratic Republic & 2007 & 300 & 8689 & 96.5 & 49.1 & 148 \\
\hline Côte d'Ivoire & $2011-12$ & 351 & 7141 & 100.3 & 50.1 & 108 \\
\hline Ethiopia & 2011 & 596 & 11597 & 108.7 & 52.1 & 88 \\
\hline Gabon & 2012 & 334 & 4908 & 106.6 & 51.6 & 65 \\
\hline Ghana & 2008 & 406 & 2783 & 106.9 & 51.7 & 80 \\
\hline Guinea & 2005 & 295 & 6034 & 107.8 & 51.9 & 163 \\
\hline Kenya & 2008-09 & 398 & 5698 & 107.1 & 51.7 & 74 \\
\hline Lesotho & 2009 & 399 & 3616 & 104.1 & 51.0 & 117 \\
\hline Liberia & 2007 & 298 & 5372 & 108.2 & 52.0 & 110 \\
\hline Madagascar & 2008-09 & 594 & 12449 & 104.0 & 51.0 & 72 \\
\hline Malawi & 2010 & 849 & 18850 & 99.4 & 49.8 & 112 \\
\hline Mali & 2006 & 407 & 13941 & 102.5 & 50.6 & 191 \\
\hline Mozambique & 2011 & 610 & 11265 & 102.8 & 50.7 & 97 \\
\hline Namibia & 2006-07 & 495 & 4832 & 104.5 & 51.1 & 69 \\
\hline Niger & 2006 & 342 & 9557 & 104.3 & 51.1 & 198 \\
\hline Nigeria & 2008 & 886 & 27141 & 103.5 & 50.9 & 157 \\
\hline Rwanda & 2010 & 492 & 8868 & 103.7 & 50.9 & 76 \\
\hline Senegal & 2010-11 & 391 & 11014 & 105.3 & 51.3 & 72 \\
\hline Sierra Leone & 2008 & 352 & 5601 & 97.5 & 49.4 & 140 \\
\hline Swaziland & 2006-07 & 274 & 2755 & 102.0 & 50.5 & 120 \\
\hline Tanzania & 2010 & 475 & 7939 & 99.6 & 49.9 & 81 \\
\hline Uganda & 2006 & 404 & 7813 & 100.7 & 50.2 & 90 \\
\hline Zambia & 2007 & 319 & 6156 & 99.2 & 49.8 & 119 \\
\hline Zimbabwe & $2010-11$ & 406 & 5444 & 101.9 & 50.5 & 84 \\
\hline
\end{tabular}

1. Number and percentages were calculated using appropriate individual country weights.

* U5M rate for the five-year period preceding the survey. (Source: ICF International, 2012. MEASURE DHS

STATcompiler - http://www.statcompiler.com - November 102013 http://www.statcompiler.com/).

except the Congo Democratic Republic $(p=0.420)$ and Tanzania $(p=0.110)$. On average, the proportion of births where mothers have deemed their infants as being average or larger than average was significantly higher for boys. Gender preference for children was investigated, using fertility preference, to determine whether there is son preference. The findings reveal that the proportion of births among mothers who have a son preference was significantly higher for boys $(p<=0.005)$. There is no difference between boys and girls by delivery care provider (in all countries but Burundi, Guinea, Malawi, and Mozambique). The proportion of newborns with deliveries assisted by doctor 
Boco: Assessing sex differentials in under-five mortality in sub-Saharan Africa

or nurse/midwife was statistically significantly higher for boys (31.4\%) than girls $(26.9 \%)$ in 2010 in Burundi ( $\mathrm{p}=0.044)$. A similar pattern is found in 2005 in Guinea (boys $29.9 \%$ compared to girls 26.8\%, $\mathrm{p}=0.012$ ); in 2010 in Malawi (boys 72.3\%, girls 70.7\%, p=0.072), and in 2011 in Mozambique (boys 19.2\%, girls $17.6 \%, \mathrm{p}=0.057$ ).

\section{Cross-national comparison of sex differentials in under-five mortality}

Results from the multilevel discrete-time hazard models are shown in Table 2. In the interest of space, coefficients for other covariates are not displayed but are available on request. Country-specific sex differentials in U5M are expressed as odds ratios (ORs) with corresponding 95\% confidence intervals (CIs). Model 1 presents a baseline model showing only the effects of sex of child and age. Model 2 adds the effect of individual-level control variables. Model 3 includes both individual and community-level variables. Model 4 adds the interaction terms between sex and age. Comparison of the four models yields assessments of how the effect of child's sex on U5M is affected by each block of covariates and by all covariates simultaneously.

The results show systematically higher mortality for male children compared to females in all countries except Sierra Leone and Swaziland. Model 1 reveals that the male/female odds ratio for U5M ranges from $1.07(95 \% \mathrm{CI}=0.97-1.18 ; \mathrm{p}=0.199)$ in Mali to $1.54(95 \% \mathrm{CI}=1.29-1.83 ; \mathrm{p}=0.000)$ in Côte d`Ivoire. In some countries (Madagascar, Chad, Niger, Congo Democratic Republic, Benin, Mali, Burundi, Rwanda, Congo (Brazzaville), Ghana, Swaziland) the differences are small or not significant at the five per cent significance level. Males have 25-54 per cent higher odds of dying before age five in the countries where the association between sex of the child and risk of mortality is significant. The countries with the widest male disadvantages in U5M tend to be found in Southern (e.g., Lesotho) and Western (e.g., Côte d'Ivoire) Africa. The risk of U5M was not different between males and females $(\mathrm{OR}=1.00 ; 95 \% \mathrm{CI}=0.78-1.29, \mathrm{p}=0.987)$ in Swaziland. On the contrary, in Sierra Leone, males have 14 per cent lower odds than females of dying before age five $(\mathrm{OR}=0.86 ; 95 \%$ $\mathrm{CI}=0.71-1.03 ; \mathrm{p}=0.091)$. Overall, sex gaps in U5M are found to vary cross-nationally.

As seen in Model 2, adjustment for individual-level factors slightly increases the ORs male to female mortality from the baseline models (age-adjusted sex differences; Model 1) in most of those thirty countries. Exceptions to this pattern are found in only three countries (Ethiopia, Tanzania, and Uganda), where the coefficients were reduced.

After adjusting for both individual-level and community-level factors together (Model 3), the sex ratio in U5M (excess mortality of males with respect to females) remains significant at the 5\% level of significance in seventeen countries: Côte d'Ivoire, Nigeria, Malawi, Guinea, Mozambique, Lesotho, Zambia, Kenya, Senegal, Ethiopia, Gabon, Cameroon, Zimbabwe, Burkina Faso, Uganda, Namibia, and Madagascar. In many cases, effect sizes do not change markedly when adjusting for the additional covariates. The individual-level and community-level controls explain less than two percent of the sex differentials in U5M in Uganda, Senegal, and Lesotho. For only two countries (Sierra Leone and Swaziland) the male U5M rate is lower than that for females. But the ORs for the association were not statistically significant.

The full model (Model 3) was examined for evidence of interaction between sex and age of children to determine whether sex disparities in U5M are affected by age. Wald tests showed that the addition of the interaction terms [male X age (1-11 months); (male X age (12-59 months)] to the full model yields a significantly improved model in twelve countries. No significant interaction between sex and age emerges in eighteen countries: Benin $(p=0.476)$, Burkina Faso $(p=0.918)$, Burundi $(p=0.320)$, Congo (Brazzaville) $(p=0.1741)$, Ethiopia $(p=0.303)$, Gabon $(p=0.717)$, Ghana 
Table 2. Odds ratios (OR), 95\% confidence intervals (CI), and p-values of dying before age five by sex of child (males versus females) in thirty sub-Saharan Africa countries, all singleton births born within the five years preceding the survey, by country, Demographic and Health Surveys, 2004-2012.

\begin{tabular}{|c|c|c|c|c|c|c|c|c|c|}
\hline \multirow[b]{2}{*}{ Country } & \multicolumn{3}{|c|}{ Model 1} & \multicolumn{3}{|c|}{ Model 2} & \multicolumn{3}{|c|}{ Model 3} \\
\hline & OR & $95 \% \mathrm{CI}$ & P-value & OR & $95 \% \mathrm{CI}$ & P-value & OR & $95 \% \mathrm{CI}$ & P-value \\
\hline Benin & 1.09 & $0.96-1.22$ & 0.176 & 1.11 & $0.98-1.25$ & 0.103 & 1.11 & $0.98-1.25$ & 0.094 \\
\hline Burkina Faso & 1.13 & $1.00-1.27$ & 0.044 & 1.13 & $1.00-1.28$ & 0.043 & 1.13 & $1.01-1.28$ & 0.039 \\
\hline Burundi & 1.11 & $0.93-1.34$ & 0.245 & 1.15 & $0.96-1.39$ & 0.135 & 1.16 & $0.96-1.39$ & 0.131 \\
\hline Cameroon & 1.15 & $1.00-1.33$ & 0.050 & 1.17 & $1.01-1.34$ & 0.034 & 1.17 & $1.01-1.35$ & 0.031 \\
\hline Chad & 1.13 & $0.96-1.32$ & 0.141 & 1.13 & $0.97-1.33$ & 0.119 & 1.14 & $0.97-1.33$ & 0.109 \\
\hline Congo (Brazzaville) & 1.08 & $0.89-1.32$ & 0.432 & 1.12 & $0.91-1.37$ & 0.283 & 1.12 & $0.91-1.37$ & 0.282 \\
\hline Congo Democratic Republic & 1.10 & $0.96-1.27$ & 0.157 & 1.12 & $0.97-1.29$ & 0.121 & 1.12 & $0.97-1.29$ & 0.122 \\
\hline Côte d'Ivoire & 1.54 & $1.29-1.83$ & 0.000 & 1.57 & $1.32-1.88$ & 0.000 & 1.58 & $1.32-1.89$ & 0.000 \\
\hline Ethiopia & 1.22 & $1.05-1.42$ & 0.008 & 1.20 & $1.03-1.39$ & 0.018 & 1.20 & $1.03-1.40$ & 0.018 \\
\hline Gabon & 1.28 & $0.99-1.65$ & 0.056 & 1.37 & $1.05-1.80$ & 0.023 & 1.37 & $1.05-1.80$ & 0.023 \\
\hline Ghana & 1.10 & $0.80-1.50$ & 0.563 & 1.10 & $0.80-1.52$ & 0.557 & 1.09 & $0.79-1.50$ & 0.595 \\
\hline Guinea & 1.27 & $1.08-1.50$ & 0.004 & 1.30 & $1.10-1.53$ & 0.002 & 1.30 & $1.10-1.54$ & 0.002 \\
\hline Kenya & 1.31 & $1.04-1.64$ & 0.020 & 1.33 & $1.05-1.67$ & 0.017 & 1.33 & $1.06-1.68$ & 0.016 \\
\hline Lesotho & 1.38 & $1.11-1.72$ & 0.004 & 1.38 & $1.10-1.72$ & 0.004 & 1.38 & $1.10-1.72$ & 0.005 \\
\hline Liberia & 1.22 & $1.00-1.49$ & 0.055 & 1.21 & $0.98-1.48$ & 0.072 & 1.21 & $0.98-1.49$ & 0.071 \\
\hline Madagascar & 1.14 & $0.97-1.34$ & 0.115 & 1.17 & $1.00-1.38$ & 0.057 & 1.18 & $1.00-1.39$ & 0.053 \\
\hline Malawi & 1.21 & $1.09-1.35$ & 0.000 & 1.23 & $1.10-1.37$ & 0.000 & 1.23 & $1.10-1.37$ & 0.000 \\
\hline Mali & 1.07 & $0.97-1.18$ & 0.199 & 1.08 & $0.97-1.20$ & 0.159 & 1.08 & $0.97-1.20$ & 0.158 \\
\hline Mozambique & 1.16 & $1.00-1.35$ & 0.049 & 1.26 & $1.07-1.47$ & 0.004 & 1.26 & $1.08-1.48$ & 0.004 \\
\hline Namibia & 1.25 & $0.98-1.58$ & 0.072 & 1.28 & $1.00-1.65$ & 0.053 & 1.28 & $1.00-1.65$ & 0.051 \\
\hline Niger & 1.11 & $0.96-1.27$ & 0.157 & 1.13 & $0.98-1.30$ & 0.090 & 1.13 & $0.98-1.30$ & 0.091 \\
\hline Nigeria & 1.18 & $1.09-1.28$ & 0.000 & 1.20 & $1.11-1.29$ & 0.000 & 1.20 & $1.11-1.29$ & 0.000 \\
\hline Rwanda & 1.11 & $0.92-1.34$ & 0.256 & 1.15 & $0.95-1.40$ & 0.140 & 1.16 & $0.96-1.40$ & 0.135 \\
\hline Senegal & 1.23 & $1.05-1.45$ & 0.013 & 1.23 & $1.04-1.45$ & 0.017 & 1.23 & $1.04-1.45$ & 0.016 \\
\hline Sierra Leone & 0.86 & $0.71-1.03$ & 0.091 & 0.86 & $0.72-1.04$ & 0.126 & 0.87 & $0.72-1.05$ & 0.139 \\
\hline Swaziland & 1.00 & $0.78-1.29$ & 0.987 & 0.97 & $0.75-1.26$ & 0.824 & 0.97 & $0.74-1.26$ & 0.817 \\
\hline Tanzania & 1.25 & $1.03-1.52$ & 0.027 & 1.22 & $0.99-1.49$ & 0.058 & 1.22 & $0.99-1.49$ & 0.057 \\
\hline Uganda & 1.24 & $1.03-1.48$ & 0.024 & 1.22 & $1.01-1.47$ & 0.038 & 1.22 & $1.01-1.47$ & 0.041 \\
\hline Zambia & 1.28 & $1.06-1.53$ & 0.009 & 1.29 & $1.07-1.55$ & 0.008 & 1.29 & $1.07-1.55$ & 0.008 \\
\hline Zimbabwe & 1.26 & $1.01-1.58$ & 0.040 & 1.29 & $1.02-1.63$ & 0.032 & 1.28 & $1.01-1.61$ & 0.039 \\
\hline
\end{tabular}

Note: control variables (not shown). Model 1 -baseline model including only sex of the child (female (ref.), male) and the age (0 months (ref.) 1-11 months, 12-59 months). Model 2-adjusting Model 1 for individual-level variables: child size at birth (average or larger than average (ref.), very small and smaller than average); birth order and preceding birth interval (first birth ((ref.), $2-3$ and $<24$ months, 2-3 and 24+ months, 4+ and $<24$ months, 4+ and 24+ months), mother's age at child birth (less than 20 years (ref.), 20-34 years, greater than 35 years), skilled attendant at delivery (other (incl. none) (ref.), doctor, nurse, or midwife), type of gender preference (no gender preference (ref), balance preference, daughter preference, son preference), maternal education (no education (ref.) primary, secondary or higher), household wealth index (1st quintile (poorest) (ref.), 2nd quintile, 3rd quintile, 4th quintile, 5th quintile (richest)). Model 3 includes individual- and community-level control (urban-rural area of residence (rural (ref.), urban), women with secondary or higher (\%) (low (ref.), high), women delivering in a health facility (\%) (low (ref.), high), women who have a son preference (\%) (low (ref.), high), mean wealth index quintile score (low (ref.), high)). Model 4 - adjusting for all of the studied independent variables and interaction terms between sex and age group. All models are multivariate multilevel logit hazards model regression $($ Ref. $=$ referent).

$(p=0.246)$, Kenya $(p=0.218)$, Liberia $(p=0.140)$, Madagascar $(p=0.786)$, Malawi $(p=0.354)$, Niger $(p=0.117)$, Rwanda $(p=0.313)$, Sierra Leone $(p=0.652)$, Swaziland $(p=0.899)$, Uganda $(p=0.362)$, Zambia ( $\mathrm{p}=0.261)$, Zimbabwe $(\mathrm{p}=0.969)$ (see Wald test (Prob $>$ chi2) in Model4 of Table 2$)$. 
Boco: Assessing sex differentials in under-five mortality in sub-Saharan Africa

Table 2 (cont'd): Model 4 and Wald test.

\begin{tabular}{|c|c|c|c|c|c|c|c|c|c|c|}
\hline \multirow[b]{2}{*}{ Country } & \multicolumn{6}{|c|}{ Model 4} & \multicolumn{3}{|c|}{ Male $X$ age: $12-59$ months } & \multirow{2}{*}{$\begin{array}{c}\text { Wald test } \\
\left(\text { Prob }>\mathrm{chi}^{2}\right)^{\prime}\end{array}$} \\
\hline & OR & $95 \% \mathrm{CI}$ & P-value & OR & $95 \% \mathrm{CI}$ & P-value & OR & $95 \% \mathrm{CI}$ & P-value & \\
\hline Benin & 1.24 & $1.00-1.54$ & 0.054 & 1.04 & $0.86-1.27$ & 0.670 & 1.07 & $0.87-1.32$ & 0.533 & 0.476 \\
\hline Burkina Faso & 1.13 & $0.90-1.42$ & 0.290 & 1.17 & $0.96-1.42$ & 0.118 & 1.10 & $0.90-1.35$ & 0.345 & 0.918 \\
\hline Burundi & 1.32 & $0.98-1.77$ & 0.064 & 1.15 & $0.85-1.56$ & 0.354 & 0.90 & $0.60-1.35$ & 0.605 & 0.320 \\
\hline Cameroon & 1.46 & $1.13-1.89$ & 0.004 & 1.22 & $0.95-1.56$ & 0.113 & 0.93 & $0.73-1.18$ & 0.541 & 0.035 \\
\hline Chad & 1.59 & $1.17-2.16$ & 0.003 & 1.02 & $0.79-1.31$ & 0.868 & 0.98 & $0.74-1.29$ & 0.876 & 0.037 \\
\hline Congo (Brazzaville) & 1.37 & $0.97-1.95$ & 0.076 & 1.15 & $0.83-1.60$ & 0.405 & 0.84 & $0.58-1.23$ & 0.378 & 0.174 \\
\hline Congo D.R. & 1.44 & $1.11-1.88$ & 0.007 & 0.98 & $0.79-1.22$ & 0.877 & 1.05 & $0.81-1.37$ & 0.707 & 0.076 \\
\hline Côte d'Ivoire & 2.16 & $1.59-2.94$ & 0.000 & 1.38 & $1.02-1.85$ & 0.035 & 1.27 & $0.91-1.76$ & 0.162 & 0.037 \\
\hline Ethiopia & 1.36 & $1.09-1.70$ & 0.007 & 1.11 & $0.85-1.46$ & 0.447 & 1.04 & $0.76-1.41$ & 0.805 & 0.303 \\
\hline Gabon & 1.40 & $0.90-2.18$ & 0.133 & 1.19 & $0.76-1.89$ & 0.447 & 1.58 & $0.95-2.63$ & 0.078 & 0.717 \\
\hline Ghana & 1.43 & $0.90-2.28$ & 0.132 & 0.94 & $0.53-1.65$ & 0.821 & 0.75 & $0.38-1.48$ & 0.404 & 0.246 \\
\hline Guinea & 1.73 & $1.28-2.32$ & 0.000 & 1.26 & $0.96-1.65$ & 0.094 & 1.00 & $0.74-1.36$ & 0.975 & 0.039 \\
\hline Kenya & 1.60 & $1.12-2.30$ & 0.010 & 1.32 & $0.90-1.93$ & 0.152 & 0.93 & $0.57-1.53$ & 0.788 & 0.218 \\
\hline Lesotho & 1.94 & $1.33-2.82$ & 0.001 & 1.12 & $0.81-1.55$ & 0.497 & 1.17 & $0.70-1.98$ & 0.547 & 0.076 \\
\hline Liberia & 1.62 & $1.13-2.33$ & 0.009 & 1.01 & $0.74-1.38$ & 0.941 & 1.12 & $0.73-1.70$ & 0.605 & 0.140 \\
\hline Madagascar & 1.14 & $0.88-1.48$ & 0.325 & 1.26 & $0.97-1.63$ & 0.081 & 1.09 & $0.76-1.56$ & 0.623 & 0.786 \\
\hline Malawi & 1.37 & $1.13-1.67$ & 0.001 & 1.18 & $0.98-1.41$ & 0.074 & 1.13 & $0.92-1.39$ & 0.228 & 0.354 \\
\hline Mali & 1.34 & $1.11-1.61$ & 0.002 & 0.96 & $0.81-1.15$ & 0.682 & 0.98 & $0.83-1.17$ & 0.854 & 0.019 \\
\hline Mozambique & 1.79 & $1.38-2.32$ & 0.000 & 1.05 & $0.82-1.35$ & 0.708 & 0.95 & $0.68-1.33$ & 0.775 & 0.003 \\
\hline Namibia & 1.95 & $1.25-3.05$ & 0.003 & 1.11 & $0.75-1.65$ & 0.588 & 0.93 & $0.56-1.52$ & 0.762 & 0.059 \\
\hline Niger & 1.46 & $1.09-1.94$ & 0.011 & 1.11 & $0.87-1.41$ & 0.418 & 1.00 & $0.80-1.24$ & 0.968 & 0.117 \\
\hline Nigeria & 1.45 & $1.26-1.66$ & 0.000 & 1.12 & $0.97-1.28$ & 0.131 & 1.07 & $0.94-1.21$ & 0.328 & 0.003 \\
\hline Rwanda & 1.36 & $1.02-1.82$ & 0.036 & 1.05 & $0.77-1.43$ & 0.761 & 0.97 & $0.63-1.47$ & 0.874 & 0.313 \\
\hline Senegal & 1.64 & $1.27-2.11$ & 0.000 & 0.81 & $0.60-1.08$ & 0.154 & 1.26 & $0.88-1.80$ & 0.217 & 0.002 \\
\hline Sierra Leone & 0.81 & $0.59-1.11$ & 0.187 & 0.96 & $0.72-1.28$ & 0.790 & 0.80 & $0.55-1.18$ & 0.260 & 0.652 \\
\hline Swaziland & 0.86 & $0.49-1.53$ & 0.615 & 1.01 & $0.72-1.41$ & 0.960 & 0.97 & $0.53-1.77$ & 0.920 & 0.899 \\
\hline Tanzania & 1.78 & $1.29-2.45$ & 0.000 & 0.73 & $0.52-1.03$ & 0.072 & 1.36 & $0.89-2.07$ & 0.155 & 0.001 \\
\hline Uganda & 1.44 & $1.05-1.96$ & 0.022 & 1.16 & $0.86-1.58$ & 0.332 & 1.03 & $0.71-1.48$ & 0.891 & 0.362 \\
\hline Zambia & 1.08 & $0.79-1.49$ & 0.623 & 1.55 & $1.15-2.10$ & 0.004 & 1.22 & $0.86-1.74$ & 0.262 & 0.261 \\
\hline Zimbabwe & 1.32 & $0.89-1.94$ & 0.164 & 1.28 & $0.88-1.87$ & 0.195 & 1.22 & $0.78-1.91$ & 0.381 & 0.969 \\
\hline
\end{tabular}

* Wald test $\left(\right.$ Prob $\left.>\mathrm{chi}^{2}\right)$ indicates whether the model with interaction terms as predictors (Model 4) fits significantly better than a model without interaction terms (Model 3).

The analysis set out to examine the main effect of child's sex on U5M and the underlying mechanisms at work across sub-Saharan African countries. The introduction of interaction terms does not change the magnitude and the direction of effects. Even after accounting for key covariates, including biological indicators of health (e.g., birth weight, birth order, and preceding birth interval), gender preference, and household and community socio-economic and environmental characteristics, as well as interaction of sex with age, there was a very strong association between child's sex and risk of dying before age five.

Excess male U5M persists and remains significant in nineteen countries (Nigeria, Côte d'Ivoire, Mozambique, Senegal, Guinea, Tanzania, Lesotho, Malawi, Mali, Chad, Namibia, Cameroon, Ethiopia, Congo Democratic Republic, Liberia, Kenya, Niger, Uganda, and Rwanda) ( $<<0.05$ )(see the ORs of the main effects in Model 4 of Table 2). The change in sex differentials in U5M observed 
across models (Model 1 to Model 4) is very small or insignificant. Overall, cross-national differences do not disappear after the introduction of the control variables in Models 2, 3, and 4. The adjusted ORs for the sex of newborns on U5M remain largely unchanged, or increased. This suggests that the child's sex is an independent predictor of U5M in these countries. The individual-level (child, mother, and household characteristics) and community-level control variables in this study do not explain the sex differentials in U5M in many countries in sub-Saharan Africa.

\section{Discussion and conclusion}

The issue of sex differentials in childhood mortality in LDCs has recently generated considerable interest. Sex-disparities in childhood mortality may be explained by various factors, and previous studies are limited in examining the role of individual, household, and community-level factors. Using multilevel discrete time-hazard modeling to analyze the Demographic and Health Survey data for thirty Sub-Saharan Africa countries, this article empirically assesses country-specific sex differentials in U5M rates, while controlling for observed individual, household, and community-level characteristics as well as community-level effects.

The results show that male children have systematically higher mortality risks than female children. In particular, boys' U5M was about 17-54 per cent higher than girls'. These patterns were found even with controls for individual and community-level factors, as well as heterogeneity. Overall, the results are consistent with long-established findings of higher infant mortality in males, which have persisted for many years and occur among most world populations, and have been explained in part by differences in genetic gender susceptibility to disease (Drevenstedt et al. 2008; Pongou 2013). These findings suggest the pattern of male excess childhood mortality is present across countries in SSA. Some studies have highlighted sex differences despite the fact that this was not the principal aim of the study (Madise et al. 2003). Excess male infant mortality has been previously observed in Africa (see LeGrand and Mbacké 1995; United Nations 2011). In analysis of the contributing determinants of wealth-related inequality in U5M in thirteen African countries, Van Malderen et al. (2013) have revealed an independent effect of the sex of the child; mortality was higher in males in Lesotho, Malawi, Nigeria and São Tomé and Príncipe. On the other hand, a community-based cohort study in rural Malawi has documented a twofold mortality risk among 1-year-old to 2-year-old boys compared with girls of the same age (Ashorn et al. 2002).

Most of the literature claims that the poorer health of boys may reflect biological factors (see Waldron 1983; Pollard and Hyatt 1999; Kalben 2000; Vallin 2006). Indeed, male disadvantage in mortality is most likely explained by biological factors such as lower resistance to infection, higher risk of premature birth, and larger average birthweight and head circumference leading to difficult labour (Wells 2000; Van Malderen 2013: 4332). Waldron notes that male infants have "inherently lower levels of certain components of immune resistance, and this may contribute to a higher mortality risk of some types of infectious disease" (Waldron 1983, 1987). In this study, however, it was difficult to attribute to the effect of hidden biological factors on residual sex differences in U5M, after controlling for heterogeneity at individual levels (due to known environmental and biological factors) and for heterogeneity at community levels (due to unknown environmental and biological factors). In many countries, the individual and community-level factors do not account for sex differentials in U5M risk. It is hard to explain completely the sex gap in U5M that varies nationally. Many scholars have highlighted that determinants of sex differences in mortality are far from being certain, and their combination into integrated biological models continues to be inadequate. A particular difficulty is to distinguish between environmental fac- 
Boco: Assessing sex differentials in under-five mortality in sub-Saharan Africa

tors that occur around the time of conception and purely biological factors (e.g., genetics; Bharadwaj and Lakdawala 2013; Pongou 2013). In addition, it is almost impossible in population-based data (e.g., DHS) to control directly for all biological factors. The literature further suggests that sex differences in childhood mortality may be attributable to differences in socio-cultural, political, and economic systems that influence discrimination against girls. However, inadequate measurement of these variables has limited their consideration in previous comparative research.

The origin of sex differences in childhood mortality is complex. This study highlights the importance of the need to incorporate additional contextual variables in future analyses. One limitation of this paper is that several important causes of under- 5 death could not be included in this analysis, due to the lack of data. These include genetic causes or biological characteristic such as anemia and infection with HIV in pregnancy (Volberding et al. 2004) and cultural factors such as ethnicity (Gyimah 2006). Details of the circumstances of the individual child (breastfeeding, immunization, number of siblings who died during their first five years of life) or specific practices of the mother regarding child care and hygiene (changes, if any, in the food or water given to children when they suffered from fever or diarrhea, regularity in use of soap, frequency of bathing) could not be included. Children under 5 can be highly susceptible to infectious illnesses, accounting for nearly two-thirds of deaths (Tsai 2012; Campbell et al. 2013). A recent UNICEF report notes that pneumonia, diarrhea, malaria, meningitis, tetanus, and measles are common childhood illnesses, and these are deaths which can be easily prevented by prioritizing the poorest children. Many deaths from infectious diseases occur in children who are already weakened by undernutrition (UNICEF 2012). It should also be noted that in this study, multilevel modeling takes account of unobserved heterogeneity at the community level. In addition, to ensure comparability and consistency, only a limited number of variables are used in this study. As the comparability between surveys is more important than the model selection process, all variables that are comparable in all thirty datasets are included in the analysis. It is possible, however, that others observable mechanisms lead to excess male U5M across the Sub-Saharan region. Notwithstanding these limitations, the findings from this study represent a further step towards an improved understanding of the complex determinants of child survival in sub-Saharan Africa.

\section{Acknowledgement}

I am grateful to the Editor/Guest Editor and two anonymous referees for insightful comments and suggestions that have helped improve the paper. I would like to thank Sarah Bradley and Trevor Croft from ICF International for their helpful comments on the attitudinal measures of gender preference for children, using DHS data. I am grateful to Dr. Susan McDaniel at the Prentice Institute for Global Population and Economy for her valuable editing and encouragements.

\section{References}

Aaby, P., M.L. Garly, J. Nielsen, H. Ravn, C. Martins, C. Balé, A. Rodrigues, C.S. Benn, and I.M. Lisse.

2007. Increased female-male mortality ratio associated with inactivated polio and diphtheria-tetanuspertussis vaccines: Observations from vaccination trials in Guinea-Bissau. Pediatric Infectious Disease Journal 26(3):247.

Aliaga, A., and R. Ren. 2006. The Optimal Sample Sizes for Two-Stage Cluster Sampling in Demographic and Health Surveys. DHS Working Papers No. 30. Calverton MD: ORC Macro.

Allison, P.D. 1982. Discrete-time methods for the analysis of event histories. Sociological Methodology 13:61-98. 
Arnold, F. 1990. Assessment of the Quality of Birth History Data in the Demographic and Health Surveys: An Assessment of DHS-I Data Quality. Demographic and Health Surveys Methodological Reports No 1. Columbia (MD): Institute for Resource Development/Macro Systems.

Arokiasamy, P. 2004. Regional patterns of sex bias and excess female child mortality in India. Population (English Edition, 2002-) 59(6):833-863.

Ashorn, P., K. Maleta, M. Espo, and T. Kulmala. 2002. Male biased mortality among 1-2 year old children in rural Malawi. Archives of Disease in Childhood 87(5):386-387.

Baron, R.M., and D.A. Kenny. 1986. The moderator-mediator variable distinction in social psychological research: Conceptual, strategic, and statistical considerations. Journal of Personality and Social Psychology 51(6):1173-1182.

Bernard, P., R. Charafeddine, K.L. Frohlich, M. Daniel, Y. Kestens, and L. Potvin. 2007. Health inequalities and place: A theoretical conception of neighbourhood. Social Science \& Medicine 65(9):1839-1852.

Bharadwaj, P., and L.K. Lakdawala. 2013. Discrimination begins in the womb: Evidence of sex-selective prenatal investments. Journal of Human Resources 48(1):71-113.

Bhutta, Z.A., T. Ahmed, R.E. Black, S. Cousens, K. Dewey, E. Giugliani, B.A. Haider, B. Kirkwood, S.S. Morris, H.P.S. Sachdev, and M. Shekar. 2008. What works? Interventions for maternal and child undernutrition and survival. Lancet 371(9610):417-440.

Biaye, M. 1994. Inégalités sexuelles en matière de santé, de morbidité et de mortalité dans l'enfance dans trois pays de l'Afrique de l'ouest: hypothèses, mesures et recherche d'explication des mécanismes. Louvain-la-Neuve: L'Harmattan/Editions Academia.

Bicego, G., and O.B. Ahmad. 1996. Infant and Child Mortality. DHS Comparative Studies No. 20. Calverton MD: Macro International Inc.

Bingenheimer, J.B., and S.W. Raudenbush. 2004. Statistical and substantive inferences in public health: Issues in the application of multilevel models. Annual Review of Public Health 25(1):53-77.

Boyle, M.H., Y. Racine, K. Georgiades, D. Snelling, S. Hong, W. Omariba, P. Hurley, and P. RaoMelacini. 2006. The influence of economic development level, household wealth and maternal education on child health in the developing world. Social Science \& Medicine 63(8):2242-2254.

Byass, P., A. Worku, A. Emmelin, and Y. Berhane. 2007. DSS and DHS: Longitudinal and crosssectional viewpoints on child and adolescent mortality in Ethiopia. Population Health Metrics 5(1):12.

Campbell, C.D., and J.Z. Lee. 2009. Long-term mortality consequences of childhood family context in Liaoning, China, 1749-1909. Social Science \& Medicine 68(9):1641-1648.

Campbell, H., S. El Arifeen, T. Hazir, J. O’Kelly, J. Bryce, I. Rudan, and S.A. Qazi. 2013. Measuring coverage in $\mathrm{MNCH}$ : Challenges in monitoring the proportion of young children with pneumonia who receive antibiotic treatment. PLoS Medicine 10(5):e1001421.

Caulfield, L.E., S.A. Richard, and R.E. Black. 2004. Undernutrition as an underlying cause of malaria morbidity and mortality in children less than five years old. American Journal of Tropical Medicine \& Hygiene 71(2_suppl):55-63.

Chen, J., Z. Xie, and H. Liu. 2007. Son preference, use of maternal health care, and infant mortality in rural China, 1989 to 2000. Population Studies 61(2):161-183. 
Boco: Assessing sex differentials in under-five mortality in sub-Saharan Africa

Corsi, D.J., C.K. Chow, S.A. Lear, M.O. Rahman, S.V. Subramanian, and K.K. Teo. 2011. Shared environments: A multilevel analysis of community context and child nutritional status in Bangladesh. Public Health Nutrition 14(6):951-959.

Das Gupta, M. 1997. Socioeconomic status and clustering of child deaths in rural Punjab. Population Studies 2:191-202.

Debes, A., A. Kohli, N. Walker, K. Edmond, and L. Mullany. 2013. Time to initiation of breastfeeding and neonatal mortality and morbidity: A systematic review. BMC Public Health 13(Suppl 3):S19.

Desai, S., and S. Alva. 1998. Maternal education and child health: Is there a strong causal relationship? Demography 35(1):71-81.

Desgrées du Loû, A., G. Pison, and P. Aaby. 1995. Role of immunizations in the recent decline in childhood mortality and the changes in the female/male mortality ratio in rural Senegal. American Journal of Epidemiology 142(6):643-652.

DeWitte, S.N. 2010. Sex differentials in frailty in medieval England. American Journal of Physical Anthropology 143(2):285-297.

Dodoo, F.N.-A., and A.E. Frost. 2008. Gender in African population research: The fertility/ reproductive health example. Annual Review of Sociology 34(1):431-452.

Drevenstedt, G.L., E.M. Crimmins, S. Vasunilashorn, and C.E. Finch. 2008. The rise and fall of excess male infant mortality. Proceedings of the National Academy of Sciences 105(13):5016-5021.

Edvinsson, S., and A. Janssens. 2012. Clustering of deaths in families: Infant and child mortality in historical perspective. Biodemography and Social Biology 58(2):75-86.

FAO. 2001. Agricultural Censuses and Gender Considerations: Concept and Methodology. Rome: Food and Agriculture Organization of the United Nations (FAO), Economic and Social Development Department.

Filmer, D., E.M. King, and L. Pritchett. 1998. Gender Disparity in South Asia: Comparisons between and Within Countries. World Bank Development Research Group, Poverty and Human Resources, Policy Research Working Paper No. 1867. Washington DC: The World Bank.

Forste, R. 1994. The effects of breastfeeding and birth spacing on infant and child mortality in Bolivia. Population Studies 48(3):497-511.

Frankenberg, E. 1995. The effects of access to health care on infant mortality in Indonesia. Health Transition Review 5(2):143-163.

Fuse, K. 2010. Variations in attitudinal gender preferences for children across 50 less-developed countries. Demographic Research 23(36):1031-1048.

Fuse, K., and E.M. Crenshaw. 2006. Gender imbalance in infant mortality: A cross-national study of social structure and female infanticide. Social Science \& Medicine 62(2):360-374.

Gage, A.J. 2007. Barriers to the utilization of maternal health care in rural Mali. Social Science \& Medicine 65(8):1666-1682.

Garenne, M. 2003. Sex differences in health indicators among children in African DHS surveys. Journal of Biosocial Science 35(04):601-614.

Garenne, M., and M. Lafon. 1998. Sexist diseases. Perspectives in Biological Medicine 41(2):176-189. 
Garenne, M., and J. van Ginneken. 1994. Comparison of retrospective surveys with a longitudinal follow-up in Senegal: SFS, DHS and Niakhar. European Journal of Population/Revue européenne de Démographie 10(3):203-221.

Garfield, C.F., and A.J. Isacco Iii. 2012. Urban fathers' involvement in their child's health and healthcare. Psycbology of Men \& Masculinity 13(1):32.

Goldstein, H. 2010. Multilevel Statistical Models. 4th edn. London: Edward Arnold.

Guo, G., and L.M. Grummer-Strawn. 1993. Child mortality among twins in less developed countries. Population Studies 47(3):495-510.

Gyimah, S.O. 2006. Cultural background and infant survival in Ghana. Ethnography and Health 11(2):101-120.

- 2009. Polygynous marital structure and child survivorship in sub-Saharan Africa: Some empirical evidence from Ghana. Social Science \& Medicine 68(2):334-342.

Hancioglu, A., and F. Arnold. 2013. Measuring coverage in MNCH: Tracking progress in health for women and children using DHS and MICS household surveys. PLoS Medicine 10(5):e1001391.

Handa, S., S. Koch, and S.W. Ng. 2010. Child mortality in eastern and southern Africa. Population Review 49(1).

Hazzard, W.R. 1986. Biological basis of the sex differential in longevity. Journal of the American Geriatric Society 34(6):455-471.

Heaton, T.B., R. Forste, J.P. Hoffmann, and D. Flake. 2005. Cross-national variation in family influences on child health. Social Science \& Medicine 60(1):97-108.

Hill, K. 2003. Frameworks for studying the determinants of child survival. Bulletin of the World Health Organization 81(2):138-139.

Hill, K., and Y. Choi. 2006. Neonatal mortality in the developing world. Demographic Research 14(18):429_452.

Hill, K., and D.M. Upchurch. 1995. Gender differences in child health: Evidence from the Demographic and Health Surveys. Population and Development Review 21(1):127-151.

Hill, K., D. You, M. Inoue, M.Z. Oestergaard, and E. Technical Advisory Group of the United Nations Inter-agency Group for Child Mortality. 2012. Child mortality estimation: Accelerated progress in reducing global child mortality, 1990-2010. PLoS Medicine 9(8):e1001303.

Hobcraft, J.N., J.W. McDonald, and S.O. Rutstein. 1985. Demographic determinants of infant and early child mortality: A comparative analysis. Population Studies 39(3):363-385.

Houweling, T., A. Kunst, and J. Mackenbach. 2003. Measuring health inequality among children in developing countries: Does the choice of the indicator of economic status matter? International Journal for Equity in Health 2(1):8.

ICF International. 2012. Demographic and Health Survey Sampling and Household Listing Manual. Calverton MD: MEASURE DHS, ICF International

Justesen, A., and A. Kunst. 2000. Postneonatal and child mortality among twins in Southern and Eastern Africa. International Journal of Epidemiology 29(4):678-683.

Kalben, B.B. 2000. Why men die younger: Causes of mortality differences by sex. North American Actuarial Journal 4(4):83-111.

Kishor, S. 1993. "May God give sons to all": Gender and child mortality in India. American Sociological Review 58(2):247-265. 
Boco: Assessing sex differentials in under-five mortality in sub-Saharan Africa

Kravdal, Ø. 2004. Child mortality in India: The community-level effect of education. Population Studies 58(2):177-192.

Kuate-Defo, B. 2001. Modelling hierarchically clustered longitudinal survival processes with applications to childhood mortality and maternal health. Canadian Studies in Population 28(2):535-561.

Larsen, U., W. Chung, and M.D. Gupta. 1998. Fertility and son preference in Korea. Population Studies 52(3):317-325.

Leckie, G., and C. Charlton. 2013. runmlwin: A program to run the MLwiN multilevel modeling software from within Stata. Journal of Statistical Software 52(11):1-40.

LeGrand, T. 2000. Compte rendu: United Nations. Too Young to Die: Genes or Gender? New York, United Nations Population Division, 1998, 260 pages. (ST/ESA/SER.A/155). Cabiers québécois de démographie 29(2):365-372.

LeGrand, T., and C. Mbacké. 1995. Sex differences in mortality among young children in the Sahel. Population Bulletin of the United Nations 39:79-111.

Li, S., C. Zhu, and M.W. Feldman. 2004. Gender differences in child survival in contemporary rural China: A county study. Journal of Biosocial Science 36(1):83-109.

Luy, M. 2003. Causes of male excess mortality: Insights from cloistered populations. Population and Development Review 29(4):647-676.

Madise, N.J., E.M. Banda, and K.W. Benaya. 2003. Infant mortality in Zambia: Socioeconomic and demographic correlates. Social Biology 50(1-2):148-166.

Malqvist, M., D.T. Hoa, and S. Thomsen. 2012. Causes and determinants of inequity in maternal and child health in Vietnam. BMC Public Health 12(1):641.

Manda, S.O.M. 1998. Unobserved family and community effects on infant mortality in Malawi. Genus 47:1841-1854.

1999. Birth intervals, breastfeeding and determinants of childhood mortality in Malawi. Social Science \& Medicine 48(3):301-312.

Masuy-Stroobant, G. 2006. The determinants of infant health and mortality, in Demography: Analysis and Synthesis, 4 vols., edited by G. Caselli, G. Wunsch, and J. Vallin. San Diego: Academic Press Inc., pp. 71-79.

Mazumdar, S. 2012. Assessing vulnerability to chronic undernutrition among under-five children in Egypt: Contextual determinants of an individual consequence. International Journal of Population Research 2012:12. doi: http://dx.doi.org/10.1155/2012/939541

McHale, S.M., and T.L. Huston. 1984. Men and women as parents: Sex role orientations, employment, and parental roles with infants. Child Development 55(4):1349-1361.

MEASURE DHS. 2012. Questionnaires and Modules. http://www.measuredhs.com/What-We-Do/ Survey-Types/DHS-Questionnaires.cfm (retrieved November 2, 2012).

. n.d. Demographic and Health Surveys: Survey process. http://www.measuredhs.com/WhatWe-Do/Survey-Process.cfm (retrieved November 2, 2012).

Miller, B.D. 1981. The Endangered Sex: Neglect of Female Children in Rural North India. Ithaca and London: Cornell University Press. 
Mishra, V., T.K. Roy, and R.D. Retherford. 2004. Sex differentials in childhood feeding, health care, and nutritional status in India. Population and Development Review 30(2):269-295.

Moffitt, R. 2005. Remarks on the analysis of causal relationships in population research. Demography 42(1):91-108.

Monden, C.W., and J. Smits. 2013. Maternal education is associated with reduced female disadvantages in under-five mortality in sub-Saharan Africa and southern Asia. International Journal of Epidemiology 42(1):211-218.

Mosley, W.H., and L.C. Chen. 1984. An analytical framework for the study of child survival in developing countries. Population and Development Review 10(Supplement: Child Survival: Strategies for Research):25-45.

Omariba, D.W.R., and M.H. Boyle. 2007. Family structure and child mortality in sub-Saharan Africa: Cross-national effects of polygyny. Journal of Marriage and Family 69(2):528-543.

Pamuk, E.R., R. Fuchs, and W. Lutz. 2011. Comparing relative effects of education and economic resources on infant mortality in developing countries. Population Development Review 37(4):637-664.

Pham, T., P. Kooreman, R. Koning, and D. Wiersma. 2013. Gender patterns in Vietnam's child mortality. Journal of Population Economics 26(1):303-322.

Pollard, T.M., and S.B. Hyatt (eds.). 1999. Sex, Gender and Health. Cambridge University Press.

Pongou, R. 2013. Why is infant mortality higher in boys than in girls? A new hypothesis based on preconception environment and evidence from a large sample of twins. Demography 50(2):421-444.

Pullum, T.W. 2008. An Assessment of the Quality of Data on Health and Nutrition in the DHS Surveys, 19932003. DHS Methodological Reports 6. Calverton MD: Macro International Inc.

Rajaratnam, J.K., J.R. Marcus, A.D. Flaxman, H. Wang, A. Levin-Rector, L. Dwyer, M. Costa, A.D. Lopez, and C.J.L. Murray. 2010. Neonatal, postneonatal, childhood, and under-5 mortality for 187 countries, 1970-2010: A systematic analysis of progress towards Millennium Development Goal 4. The Lancet 375(9730):1988-2008.

Rasbash, J., F. Steele, [and] B.W.J. and H. Goldstein. 2012. A User's Guide to MLwiN. Version 2.26. Bristol: Centre for Multilevel Modelling, University of Bristol.

Ren, X.S. 1995. Sex differences in infant and child mortality in three provinces in China. Social Science \& Medicine 40(9):1259-1269.

Retherford, R.D., M.K. Choe, S. Thapa, and B.B. Gubhaju. 1989. To what extent does breastfeeding explain birth-interval effects on early childhood mortality? Demography 26(3):439-450.

Rieker, P.P., and C.E. Bird. 2005. Rethinking gender differences in health: Why we need to integrate social and biological perspectives. The Journals of Gerontology Series B: Psychological Sciences and Social Sciences 60(Special Issue 2):S40-S47.

Rogers, R.G., B.G. Everett, J.M.S. Onge, and P.M. Krueger. 2010. Social, behavioral, and biological factors, and sex differences in mortality. Demograpby 47(3):555-578.

Rosenstock, S., J. Katz, L.C. Mullany, S.K. Khatry, S.C. LeClerq, G.L. Darmstadt, and J.M. Tielsch. 2013. Sex differences in neonatal mortality in Sarlahi, Nepal: The role of biology and environment. Journal of Epidemiology and Community Health 67(12):986-991. 
Boco: Assessing sex differentials in under-five mortality in sub-Saharan Africa

Rousham, E.K. 1999. Gender bias in South Asia: Effects on child growth and nutritional status, in Sex, Gender and Health, edited by T.M. Pollard and S.B. Hyatt: Cambridge University Press, pp. 37-52.

Rutstein, S.O. 2008. Further Evidence of the Effects of Preceding Birth Intervals on Neonatal, Infant, and UnderFive-Years Mortality and Nutritional Status in Developing Countries: Evidence from the Demographic and Health Surveys. DHS Working Papers No. 41, Calverton MD: Macro International Inc.

Rutstein, S.O., and J. Kiersten. 2004. The DHS Wealth Index. DHS Comparative Reports No. 6. Calverton MD: ORC Macro.

Saha, U.R., and A. van Soest. 2011. Infant death clustering in families: Magnitude, causes, and the influence of better health services, Bangladesh 1982-2005. Population Studies 65(3):273-287.

Sastry, N. 1996. Community characteristics, individual and household attributes, and child survival in Brazil. Demography 33(2):211-229.

Sawyer, C.C. 2012. Child mortality estimation: Estimating sex differences in childhood mortality since the 1970s. PLoS Medicine 9(8): e1001287.

Sear, R., F. Steele, I.A. McGregor, and R. Mace. 2002. The effects of kin on child mortality in rural Gambia. Demography 39(1):43-63.

Singer, J.D., and J.B. Willett. 2003. Applied Longitudinal Data Analysis: Modeling Change and Event Occurrence. New York: Oxford University Press.

Singh, A., S. Chalasani, M.A. Koenig, and B. Mahapatra. 2012. The consequences of unintended births for maternal and child health in India. Population Studies 66(3):223-239.

Snijders, T.A.B., and R.J. Bosker. 2012. Multilevel Analysis: An Introduction to Basic and Advanced Multilevel Modeling. London: Sage Publications Limited.

Stephenson, R., A. Baschieri, S. Clements, M. Hennink, and N. Madise. 2006. Contextual influences on the use of health facilities for childbirth in Africa. American Journal of Public Health 96(1):84-93.

Tabutin, D., C. Gourbin, and G. Beninguisse. 2001. Surmortalité et santé des petites filles en Afrique: Tendances des années 1970 aux années 1990, in Genre et sociétés en Afrique: Implications pour le développement, edited by T. Locoh. Paris: INED, pp. 137-170.

Trovato, F., and N.M. Lalu. 1996. Narrowing sex differentials in life expectancy in the industrialized world: Early 1970's to early 1990’s. Biodemography and Social Biology 43(1-2):20-37.

Tsai, T. 2012. Child survival shows progress, but burden still heavy for poorest countries. Population Reference Bureau (November 2012). http://www.prb.org/Publications/Articles/2012/unicef-childsurvival.aspx

UN IGME. 2013. Levels \& Trends in Child Mortality: Report 2013. New York: United Nations Children's Fund.

UNICEF. 2012. Committing to Child Survival: A Promise Renewed, Progress Report 2012. New York: United Nations Children's Fund.

United Nations. 1998. Too Young to Die: Genes or Gender? New York: United Nations Dept. of Economic and Social Affairs, Population Division (ST/ESA/SER.A/155).

. 2011. Sex Differentials in Childhood Mortality. New York: Department of Economic and Social Affairs Population Division, United Nations. 
Vallin, J. 2006. Mortality, sex, and gender: Demography, analysis and synthesis-A treatise, in Population Studies, edited by G. Caselli, J. Vallin, and G. Wunsch. Amsterdam: Elsevier, pp. 177-194.

Van Bodegom, D., U.K. Eriksson, J.J. Houwing-Duistermaat, and R.G.J. Westendorp. 2012. Clustering of child mortality in a contemporary polygamous population in Africa. Biodemography and Social Biology 58(2):162-172.

Van de Poel, E., O. O'Donnell, and E. Van Doorslaer. 2009. What explains the rural-urban gap in infant mortality: Household or community characteristics? Demography 46(4):827-850.

van Ham, M., D. Manley, N. Bailey, L. Simpson, and D. Maclennan (eds.). 2012. Neighbourhood Effects Research: New Perspectives. New York: Springer.

Van Malderen, C., H. Van Oyen, and N. Speybroeck. 2013. Contributing determinants of overall and wealth-related inequality in under-5 mortality in 13 African countries. Journal of Epidemiology and Community Health 67(8):667-676.

Volberding, P.A., A.M. Levine, D. Dieterich, D. Mildvan, R. Mitsuyasu, M. Saag, and Anemia in HIV Working Group. 2004. Anemia in HIV infection: Clinical impact and evidence-based management strategies. Clinical Infectious Diseases 38(10):1454-1463. doi: 10.1086/383031.

Waldron, I. 1983. Sex differences in human mortality: The role of genetic factors. Social Science \& Medicine 17(6):321-333.

- 1987. Patterns and causes of excess female mortality among children in developing countries. World Health Statistics Quarterly 40(3):194-210.

1998. Sex differences in infant and early childhood mortality: Major causes of death and possible biological causes: Too Young to Die: Genes or Gender, edited by United Nations. New York: United Nations, pp. 64-83.

Wamani, H., A. Astrom, S. Peterson, J. Tumwine, and T. Tylleskar. 2007. Boys are more stunted than girls in Sub-Saharan Africa: A meta-analysis of 16 demographic and health surveys. BMC Pediatrics $7(1): 17$.

Wang, H., L. Dwyer-Lindgren, K.T. Lofgren, J.K. Rajaratnam, J.R. Marcus, A. Levin-Rector, C.E. Levitz, A.D. Lopez, and C.J.L. Murray. 2012. Age-specific and sex-specific mortality in 187 countries, 1970-2010: A systematic analysis for the Global Burden of Disease Study 2010. The Lancet 380(9859):2071-2094.

Wells, J.C.K. 2000. Natural selection and sex differences in morbidity and mortality in early life. Journal of Theoretical Biology 202(1):65-76.

Whitehead, M. 1992. The concepts and principles of equity and health. International Journal of Health Services 22(3):429-445.

Wong, G.Y., and W.M. Mason. 1985. The hierarchical logistic regression model for multilevel analysis. Journal of the American Statistical Association 80(391):513-524.

Yount, K.M. 2001. Excess mortality of girls in the Middle East in the 1970s and 1980s: Patterns, correlates and gaps in research. Population Studies 55(3):291-308.

Zvara, B.J., S.J. Schoppe-Sullivan, and C.K. Dush. 2013. Fathers' involvement in child health care: Associations with prenatal involvement, parents' beliefs, and maternal gatekeeping. Family Relations 62(4):649-661. 
Appendix Table 1. Average number of children (all singleton births born within the five years preceding the survey) per cluster in thirty sub-Saharan Africa countries, Demographic and Health Survey (DHS), 2004-2012.

\begin{tabular}{lcrrrr}
\hline \multicolumn{1}{c}{ Country } & $\begin{array}{c}\text { Number } \\
\text { of sample } \\
\text { clusters }\end{array}$ & Mean & Std. Dev. & Min & Max \\
\hline Benin & 750 & 20.22 & 10.17 & 2 & 80 \\
Burkina Faso & 573 & 25.25 & 9.63 & 4 & 62 \\
Burundi & 376 & 20.10 & 5.53 & 5 & 37 \\
Cameroon & 578 & 19.36 & 9.06 & 1 & 53 \\
Chad & 196 & 28.07 & 9.69 & 7 & 59 \\
Congo (Brazzaville) & 384 & 23.27 & 8.92 & 4 & 66 \\
Congo Democratic Republic & 300 & 29.01 & 8.70 & 7 & 61 \\
Côte d'Ivoire & 351 & 21.13 & 10.09 & 3 & 61 \\
Ethiopia & 596 & 18.96 & 9.34 & 1 & 52 \\
Gabon & 334 & 17.40 & 8.64 & 1 & 53 \\
Ghana & 406 & 7.04 & 4.08 & 1 & 28 \\
Guinea & 295 & 20.45 & 9.02 & 4 & 49 \\
Kenya & 398 & 14.81 & 7.76 & 1 & 44 \\
Lesotho & 399 & 9.72 & 4.60 & 1 & 38 \\
Liberia & 298 & 18.70 & 7.68 & 1 & 43 \\
Madagascar & 594 & 20.56 & 8.43 & 5 & 49 \\
Malawi & 849 & 22.50 & 7.85 & 3 & 49 \\
Mali & 407 & 33.84 & 11.45 & 7 & 68 \\
Mozambique & 610 & 17.47 & 6.93 & 2 & 48 \\
Namibia & 495 & 10.13 & 4.84 & 1 & 26 \\
Niger & 342 & 25.83 & 9.98 & 4 & 57 \\
Nigeria & 886 & 31.25 & 15.40 & 1 & 101 \\
Rwanda & 492 & 17.75 & 5.06 & 5 & 33 \\
Senegal & 391 & 30.27 & 12.01 & 6 & 67 \\
Sierra Leone & 352 & 15.42 & 7.02 & 1 & 40 \\
Swaziland & 274 & 9.99 & 5.03 & 1 & 26 \\
Tanzania & 475 & 16.38 & 8.00 & 2 & 45 \\
Uganda & 404 & 18.88 & 7.31 & 2 & 43 \\
Zambia & 319 & 19.23 & 8.85 & 3 & 60 \\
Zimbabwe & 406 & 13.35 & 6.03 & 1 & 33 \\
\hline
\end{tabular}


Appendix Table 2. Measurement of independent variables included in analyses.

Names Description

\section{Individual-level variable}

Sex

Age of the child in months

Child size at birth

Birth order and preceding birth interval

Mother's age at child birth

Type of gender preference

Mother's education

Household wealth Index

Skilled attendant at delivery

\section{Community-level variable}

Urban

Community-level socioeconomic status

Community-level education

Community hospital delivery

Women who have a son preference $(\%)$
Whether the child is male or female $(1=$ male; $0=$ female $)$.

Number of months from time of birth until time of death or censoring (interview) (categorized as $0=0$ months; $1=1$ to 11 months; $2=12$ to 59 months).

Mothers' perception of child size at birth recorded as (1=Very small, Smaller than average; $0=$ Average Larger than average, Very large)

Birth order and preceding birth interval were combined in one variable and is classified as follows: first birth, birth order 2-4 with short birth interval ( $<24$ months), birth order 2-4 with medium birth interval (24-47 months), birth order 2-4 with long birth interval (48+ months), birth order $5+$ with short birth interval $(<24$ months), birth order $5+$ with medium birth interval (24-47 months), birth order 5+ with long birth interval (48+ months).

Respondent's age (in years) at child birth ( $1=$ less than 20 years; $2=20-34$ years; 3 = greater than 35 years.

Mother's gender preference for children $(1=$ no gender preference; $2=$ balance preference; $3=$ daughter preference; $4=$ son preference).

Categorical variable indicating highest educational level that respondents completed $(1=$ no education; $2=$ primary; $3=$ secondary or higher education $)$.

Index provided with the dataset is used. DHS program provides a composite index of household amenities based on the principal component analysis (PCA) and classified the population into quintiles: (1st quintile (Poorest); 2nd quintile; 3 rd quintile; 4th quintile and 5th quintile (Richest). A quintile is assigned to each household as a measure of its relative socioeconomic level (for details see Rutstein and Johnson, 2004).

Deliveries assisted by either doctor, nurse/midwife categorized as 1 ; if other (incl. none) then categorized as 0 .

Whether the cluster is urban community according the definition of the country categorized as 1 ; if cluster is rural community then categorized as 0 .

Dichotomous variables indicating whether the weighted mean wealth quintile score for all households within the community is low or high (split at the median representing high and low mean).

Dichotomous variables indicating whether the proportion of women aged 15-49 in the community with secondary or higher education is high or low (cut-off at median proportion).

Dichotomous variables indicating whether the percentage of mothers who delivered their children in the hospital in the community is low or high (cutoff at median proportion).

Dichotomous variables indicating whether the proportion of women who reported a son as the type of gender preference for children in the community is low or high (cut-off at median proportion). 
Boco: Assessing sex differentials in under-five mortality in sub-Saharan Africa

Appendix Table 3. Sample characteristics by sex (all singleton births born within the five years preceding the survey) in thirty sub-Saharan Africa countries, Demographic and Health Survey (DHS), 2004-2012.

\begin{tabular}{|c|c|c|c|c|c|c|c|c|}
\hline \multirow[t]{2}{*}{ Variables } & \multicolumn{2}{|l|}{ Benin } & \multicolumn{6}{|c|}{ Burkina Faso } \\
\hline & $\begin{array}{c}\text { Female } \\
(\%)\end{array}$ & $\begin{array}{c}\text { Male } \\
(\%)\end{array}$ & $\begin{array}{c}\text { Total } \\
(\%)\end{array}$ & p-values & $\begin{array}{c}\text { Female } \\
(\%)\end{array}$ & $\begin{array}{c}\text { Male } \\
(\%)\end{array}$ & $\begin{array}{c}\text { Total } \\
(\%)\end{array}$ & p-values \\
\hline Child size at birth & & & & $<0.001$ & & & & 0.004 \\
\hline Average or larger than average & 84.8 & 87.7 & 86.2 & & 86.7 & 88.6 & 87.7 & \\
\hline Very small and smaller than average & 15.2 & 12.3 & 13.8 & & 13.3 & 11.4 & 12.3 & \\
\hline Birth order and preceding birth interval & & & & 0.75 & & & & 0.11 \\
\hline First birth & 20.0 & 19.9 & 20.0 & & 18.5 & 19.8 & 19.1 & \\
\hline $2-3$ and $<24$ months & 5.0 & 5.2 & 5.1 & & 4.3 & 4.0 & 4.1 & \\
\hline $2-3$ and $24+$ months & 30.4 & 30.8 & 30.6 & & 29.5 & 28.6 & 29.1 & \\
\hline $4+$ and $<24$ months & 6.5 & 6.3 & 6.4 & & 6.5 & 5.9 & 6.2 & \\
\hline $4+$ and $24+$ months & 38.1 & 37.8 & 38.0 & & 41.2 & 41.7 & 41.5 & \\
\hline Mother's age at child birth & & & & 0.16 & & & & 0.55 \\
\hline Less than 20 years & 12.0 & 12.5 & 12.3 & & 15.0 & 15.3 & 15.2 & \\
\hline $20-34$ years & 75.8 & 74.5 & 75.2 & & 69.5 & 69.1 & 69.3 & \\
\hline Greater than 35 years & 12.2 & 13.0 & 12.6 & & 15.5 & 15.6 & 15.6 & \\
\hline Skilled attendant at delivery & & & & 0.27 & & & & 0.20 \\
\hline Other (incl. none) & 26.6 & 25.8 & 26.2 & & 91.2 & 90.6 & 90.9 & \\
\hline Doctor, nurse, or midwife & 73.4 & 74.2 & 73.8 & & 8.8 & 9.4 & 9.1 & \\
\hline Type of gender preference & & & & $<0.001$ & & & & $<0.001$ \\
\hline No gender preference & 29.9 & 30.1 & 30.0 & & 21.3 & 22.7 & 22.0 & \\
\hline Balance preference & 45.8 & 45.7 & 45.7 & & 35.6 & 34.7 & 35.2 & \\
\hline Daughter preference & 11.2 & 7.0 & 9.1 & & 12.5 & 9.4 & 10.9 & \\
\hline Son preference & 13.2 & 17.2 & 15.2 & & 30.6 & 33.2 & 31.9 & \\
\hline Maternal education & & & & 0.57 & & & & 0.94 \\
\hline No education & 75.3 & 74.6 & 75.0 & & 84.5 & 84.3 & 84.4 & \\
\hline Primary & 17.5 & 17.8 & 17.6 & & 10.5 & 10.8 & 10.6 & \\
\hline Secondary or higher & 7.2 & 7.5 & 7.4 & & 5.1 & 4.9 & 5.0 & \\
\hline Household wealth Index & & & & $<0.001$ & & & & 0.48 \\
\hline 1st quintile (Poorest) & 23.6 & 21.2 & 22.4 & & 20.8 & 20.8 & 20.8 & \\
\hline 2nd quintile & 20.7 & 20.1 & 20.4 & & 22.1 & 21.5 & 21.8 & \\
\hline 3rd quintile & 20.5 & 21.1 & 20.8 & & 21.9 & 21.7 & 21.8 & \\
\hline 4th quintile & 20.0 & 20.4 & 20.2 & & 20.6 & 20.7 & 20.6 & \\
\hline 5th quintile (Richest) & 15.3 & 17.2 & 16.2 & & 14.7 & 15.2 & 15.0 & \\
\hline Urban-rural area of residence & & & & 0.013 & & & & 0.28 \\
\hline Rural & 66.7 & 64.6 & 65.7 & & 83.5 & 83.1 & 83.3 & \\
\hline Urban & 33.3 & 35.4 & 34.3 & & 16.5 & 16.9 & 16.7 & \\
\hline Women with secondary or higher (\%) & & & & 0.001 & & & & 0.51 \\
\hline Low & 58.4 & 55.8 & 57.1 & & 61.6 & 61.3 & 61.5 & \\
\hline High & 41.6 & 44.2 & 42.9 & & 38.4 & 38.7 & 38.5 & \\
\hline Women birthing in a health facility (\%) & & & & 0.30 & & & & 0.12 \\
\hline Low & 49.0 & 47.9 & 48.5 & & 53.4 & 51.8 & 52.6 & \\
\hline High & 51.0 & 52.1 & 51.5 & & 46.6 & 48.2 & 47.4 & \\
\hline Women who have a son preference (\%) & & & & 0.066 & & & & 0.17 \\
\hline Low & 53.4 & 51.9 & 52.6 & & 52.5 & 51.6 & 52.0 & \\
\hline High & 46.6 & 48.1 & 47.4 & & 47.5 & 48.4 & 48.0 & \\
\hline Mean wealth index quintile score & & & & $<0.001$ & & & & 0.013 \\
\hline Low & 49.7 & 46.0 & 47.8 & & 54.0 & 52.0 & 53.0 & \\
\hline High & 50.3 & 54.0 & 52.2 & & 46.0 & 48.0 & 47.0 & \\
\hline Number of children (N: weighted) & 7466 & 7567 & 15033 & & 7285 & 7490 & 14776 & \\
\hline
\end{tabular}


Appendix Table 3 (cont'd).

\begin{tabular}{|c|c|c|c|c|c|c|c|c|}
\hline \multirow[t]{2}{*}{ Variables } & \multicolumn{4}{|l|}{ Burundi } & \multicolumn{3}{|c|}{ Cameroon } & \multirow[b]{2}{*}{ p-values } \\
\hline & $\begin{array}{c}\text { Female } \\
(\%)\end{array}$ & $\begin{array}{c}\text { Male } \\
(\%) \\
\end{array}$ & $\begin{array}{c}\text { Total } \\
(\%)\end{array}$ & p-values & $\begin{array}{c}\text { Female } \\
(\%)\end{array}$ & $\begin{array}{c}\text { Male } \\
(\%)\end{array}$ & $\begin{array}{c}\text { Total } \\
(\%)\end{array}$ & \\
\hline Child size at birth & & & & $<0.001$ & & & & $<0.001$ \\
\hline Average or larger than average & 81.3 & 85.5 & 83.4 & & 78.6 & 84.4 & 81.4 & \\
\hline Very small and smaller than average & 18.7 & 14.5 & 16.6 & & 21.4 & 15.6 & 18.6 & \\
\hline Birth order and preceding birth interval & & & & 0.66 & & & & 0.31 \\
\hline First birth & 21.1 & 20.4 & 20.8 & & 23.1 & 23.5 & 23.3 & \\
\hline $2-3$ and $<24$ months & 8.3 & 8.0 & 8.1 & & 7.7 & 7.4 & 7.5 & \\
\hline $2-3$ and $24+$ months & 25.5 & 25.7 & 25.6 & & 26.3 & 27.8 & 27.0 & \\
\hline $4+$ and $<24$ months & 8.5 & 7.5 & 8.0 & & 9.1 & 9.1 & 9.1 & \\
\hline $4+$ and $24+$ months & 36.5 & 38.4 & 37.5 & & 33.9 & 32.2 & 33.1 & \\
\hline Mother's age at child birth & & & & 0.059 & & & & 0.42 \\
\hline Less than 20 years & 9.0 & 8.7 & 8.9 & & 19.8 & 20.1 & 19.9 & \\
\hline $20-34$ years & 71.8 & 73.3 & 72.6 & & 68.9 & 68.5 & 68.7 & \\
\hline Greater than 35 years & 19.2 & 18.0 & 18.6 & & 11.3 & 11.4 & 11.4 & \\
\hline Skilled attendant at delivery & & & & 0.044 & & & & 0.11 \\
\hline Other (incl. none) & 41.2 & 38.5 & 39.8 & & 44.9 & 42.4 & 43.7 & \\
\hline Doctor, nurse, or midwife & 58.8 & 61.5 & 60.2 & & 55.1 & 57.6 & 56.3 & \\
\hline Type of gender preference & & & & $<0.001$ & & & & $<0.001$ \\
\hline No gender preference & 19.2 & 17.7 & 18.4 & & 33.0 & 33.1 & 33.0 & \\
\hline Balance preference & 39.9 & 39.4 & 39.6 & & 30.1 & 30.0 & 30.1 & \\
\hline Daughter preference & 18.0 & 14.1 & 16.0 & & 18.6 & 15.2 & 16.9 & \\
\hline Son preference & 22.9 & 28.8 & 25.9 & & 18.4 & 21.7 & 20.0 & \\
\hline Maternal education & & & & 0.52 & & & & 0.42 \\
\hline No education & 52.3 & 52.2 & 52.2 & & 29.3 & 28.6 & 29.0 & \\
\hline Primary & 41.7 & 41.5 & 41.6 & & 39.8 & 38.7 & 39.3 & \\
\hline Secondary or higher & 6.0 & 6.3 & 6.1 & & 30.9 & 32.7 & 31.8 & \\
\hline Household wealth Index & & & & 0.59 & & & & 0.93 \\
\hline 1st quintile (Poorest) & 21.1 & 19.6 & 20.3 & & 24.0 & 24.0 & 24.0 & \\
\hline 2nd quintile & 20.4 & 21.6 & 21.0 & & 21.5 & 21.4 & 21.4 & \\
\hline 3rd quintile & 21.3 & 20.3 & 20.8 & & 20.3 & 19.6 & 20.0 & \\
\hline 4th quintile & 20.0 & 20.1 & 20.0 & & 18.8 & 19.0 & 18.9 & \\
\hline 5th quintile (Richest) & 17.3 & 18.5 & 17.9 & & 15.4 & 16.0 & 15.7 & \\
\hline Urban-rural area of residence & & & & 0.81 & & & & 0.48 \\
\hline Rural & 91.8 & 91.7 & 91.8 & & 57.8 & 57.9 & 57.8 & \\
\hline Urban & 8.2 & 8.3 & 8.2 & & 42.2 & 42.1 & 42.2 & \\
\hline Women with secondary or higher (\%) & & & & 0.18 & & & & 0.61 \\
\hline Low & 64.5 & 66.7 & 65.6 & & 54.9 & 53.4 & 54.2 & \\
\hline High & 35.5 & 33.3 & 34.4 & & 45.1 & 46.6 & 45.8 & \\
\hline Women birthing in a health facility (\%) & & & & 0.39 & & & & 0.098 \\
\hline Low & 56.2 & 54.3 & 55.2 & & 50.9 & 48.9 & 49.9 & \\
\hline High & 43.8 & 45.7 & 44.8 & & 49.1 & 51.1 & 50.1 & \\
\hline Women who have a son preference $(\%)$ & & & & 0.39 & & & & 0.44 \\
\hline Low & 49.4 & 48.4 & 48.9 & & 48.7 & 48.6 & 48.6 & \\
\hline High & 50.6 & 51.6 & 51.1 & & 51.3 & 51.4 & 51.4 & \\
\hline Mean wealth index quintile score & & & & 0.28 & & & & 0.39 \\
\hline Low & 53.7 & 54.4 & 54.0 & & 50.3 & 49.4 & 49.9 & \\
\hline High & 46.3 & 45.6 & 46.0 & & 49.7 & 50.6 & 50.1 & \\
\hline Number of children (N: weighted) & 3824 & 3975 & 7798 & & 5728 & 5523 & 11251 & \\
\hline
\end{tabular}


Appendix Table 3 (cont'd).

\begin{tabular}{|c|c|c|c|c|c|c|c|c|}
\hline \multirow[t]{2}{*}{ Variables } & \multicolumn{3}{|l|}{ Chad } & \multicolumn{5}{|c|}{ Congo (Brazzaville) } \\
\hline & $\begin{array}{c}\text { Female } \\
(\%)\end{array}$ & $\begin{array}{c}\text { Male } \\
(\%) \\
\end{array}$ & $\begin{array}{c}\text { Total } \\
(\%)\end{array}$ & p-values & $\begin{array}{c}\text { Female } \\
(\%)\end{array}$ & $\begin{array}{l}\text { Male } \\
(\%)\end{array}$ & $\begin{array}{l}\text { Total } \\
(\%)\end{array}$ & p-values \\
\hline Child size at birth & & & & $<0.001$ & & & & $<0.001$ \\
\hline Average or larger than average & 66.7 & 73.1 & 70.0 & & 86.5 & 90.2 & 88.3 & \\
\hline Very small and smaller than average & 33.3 & 26.9 & 30.0 & & 13.5 & 9.8 & 11.7 & \\
\hline Birth order and preceding birth interval & & & & 0.83 & & & & 0.21 \\
\hline First birth & 17.1 & 18.0 & 17.6 & & 25.2 & 26.4 & 25.8 & \\
\hline $2-3$ and $<24$ months & 7.4 & 7.6 & 7.5 & & 6.4 & 5.2 & 5.8 & \\
\hline $2-3$ and $24+$ months & 24.0 & 22.8 & 23.4 & & 35.3 & 35.5 & 35.4 & \\
\hline $4+$ and $<24$ months & 12.8 & 13.8 & 13.3 & & 5.2 & 4.7 & 5.0 & \\
\hline $4+$ and $24+$ months & 38.6 & 37.9 & 38.2 & & 27.8 & 28.1 & 28.0 & \\
\hline Mother's age at child birth & & & & 0.27 & & & & 0.77 \\
\hline Less than 20 years & 20.2 & 22.5 & 21.4 & & 19.7 & 19.9 & 19.8 & \\
\hline $20-34$ years & 68.7 & 65.6 & 67.1 & & 68.2 & 65.8 & 67.0 & \\
\hline Greater than 35 years & 11.1 & 11.9 & 11.5 & & 12.1 & 14.2 & 13.1 & \\
\hline Skilled attendant at delivery & & & & 0.31 & & & & 0.86 \\
\hline Other (incl. none) & 97.7 & 97.5 & 97.6 & & 19.6 & 19.4 & 19.5 & \\
\hline Doctor, nurse, or midwife & 2.3 & 2.5 & 2.4 & & 80.4 & 80.6 & 80.5 & \\
\hline Type of gender preference & & & & $<0.001$ & & & & $<0.001$ \\
\hline No gender preference & 31.5 & 33.1 & 32.3 & & 19.1 & 21.0 & 20.1 & \\
\hline Balance preference & 33.4 & 34.0 & 33.7 & & 37.2 & 35.1 & 36.2 & \\
\hline Daughter preference & 13.0 & 8.8 & 10.8 & & 29.3 & 22.3 & 25.9 & \\
\hline Son preference & 22.1 & 24.1 & 23.2 & & 14.4 & 21.5 & 17.9 & \\
\hline Maternal education & & & & 0.61 & & & & 0.12 \\
\hline No education & 77.6 & 75.4 & 76.5 & & 7.1 & 7.4 & 7.2 & \\
\hline Primary & 18.6 & 20.2 & 19.4 & & 30.5 & 30.6 & 30.6 & \\
\hline Secondary or higher & 3.8 & 4.4 & 4.1 & & 62.4 & 62.0 & 62.2 & \\
\hline Household wealth Index & & & & 0.16 & & & & 0.51 \\
\hline 1st quintile (Poorest) & 16.9 & 17.2 & 17.0 & & 22.3 & 23.4 & 22.8 & \\
\hline 2nd quintile & 23.9 & 21.1 & 22.5 & & 24.1 & 23.0 & 23.5 & \\
\hline 3rd quintile & 18.5 & 20.9 & 19.7 & & 19.6 & 19.3 & 19.5 & \\
\hline 4th quintile & 22.5 & 22.3 & 22.4 & & 19.3 & 17.8 & 18.6 & \\
\hline 5th quintile (Richest) & 18.2 & 18.5 & 18.3 & & 14.7 & 16.5 & 15.6 & \\
\hline Urban-rural area of residence & & & & 0.65 & & & & 0.42 \\
\hline Rural & 81.2 & 81.1 & 81.2 & & 38.3 & 40.2 & 39.3 & \\
\hline Urban & 18.8 & 18.9 & 18.8 & & 61.7 & 59.8 & 60.7 & \\
\hline Women with secondary or higher (\%) & & & & 1.00 & & & & 0.64 \\
\hline Low & 64.1 & 62.3 & 63.2 & & 29.5 & 30.8 & 30.1 & \\
\hline High & 35.9 & 37.7 & 36.8 & & 70.5 & 69.2 & 69.9 & \\
\hline Women birthing in a health facility (\%) & & & & 0.72 & & & & 0.69 \\
\hline Low & 69.1 & 69.6 & 69.4 & & 29.9 & 30.7 & 30.3 & \\
\hline High & 30.9 & 30.4 & 30.6 & & 70.1 & 69.3 & 69.7 & \\
\hline Women who have a son preference $(\%)$ & & & & 0.70 & & & & 0.97 \\
\hline Low & 48.3 & 49.7 & 49.0 & & 48.1 & 46.8 & 47.4 & \\
\hline High & 51.7 & 50.3 & 51.0 & & 51.9 & 53.2 & 52.6 & \\
\hline Mean wealth index quintile score & & & & 0.37 & & & & 0.71 \\
\hline Low & 67.5 & 67.5 & 67.5 & & 24.5 & 25.4 & 24.9 & \\
\hline High & 32.5 & 32.5 & 32.5 & & 75.5 & 74.6 & 75.1 & \\
\hline Number of children (N: weighted) & 2865 & 2975 & 5840 & & 3954 & 3887 & 7842 & \\
\hline
\end{tabular}


Appendix Table 3 (cont'd).

\begin{tabular}{|c|c|c|c|c|c|c|c|c|}
\hline \multirow[t]{2}{*}{ Variables } & \multicolumn{4}{|c|}{ Congo Democratic Republic } & \multicolumn{2}{|c|}{ Cote d'Ivoire } & \multirow[b]{2}{*}{$\begin{array}{l}\text { Total } \\
(\%)\end{array}$} & \multirow[b]{2}{*}{ p-values } \\
\hline & $\begin{array}{c}\text { Female } \\
(\%)\end{array}$ & $\begin{array}{l}\text { Male } \\
(\%)\end{array}$ & $\begin{array}{l}\text { Total } \\
(\%)\end{array}$ & p-values & $\begin{array}{c}\text { Female } \\
(\%)\end{array}$ & $\begin{array}{l}\text { Male } \\
(\%)\end{array}$ & & \\
\hline Child size at birth & & & & 0.42 & & & & 0.061 \\
\hline Average or larger than average & 91.2 & 90.8 & 91.0 & & 84.5 & 86.3 & 85.4 & \\
\hline Very small and smaller than average & 8.8 & 9.2 & 9.0 & & 15.5 & 13.7 & 14.6 & \\
\hline Birth order and preceding birth interval & & & & 0.20 & & & & 0.15 \\
\hline First birth & 20.7 & 21.2 & 21.0 & & 23.9 & 22.2 & 23.0 & \\
\hline $2-3$ and $<24$ months & 8.6 & 7.2 & 7.9 & & 5.3 & 4.7 & 5.0 & \\
\hline $2-3$ and $24+$ months & 23.5 & 25.4 & 24.5 & & 32.1 & 31.3 & 31.7 & \\
\hline $4+$ and $<24$ months & 12.4 & 12.6 & 12.5 & & 6.4 & 6.3 & 6.4 & \\
\hline $4+$ and $24+$ months & 34.8 & 33.5 & 34.2 & & 32.4 & 35.5 & 33.9 & \\
\hline Mother's age at child birth & & & & 0.17 & & & & 0.19 \\
\hline Less than 20 years & 16.5 & 16.6 & 16.5 & & 19.1 & 16.1 & 17.6 & \\
\hline $20-34$ years & 68.4 & 67.0 & 67.7 & & 68.3 & 70.2 & 69.3 & \\
\hline Greater than 35 years & 15.1 & 16.5 & 15.8 & & 12.6 & 13.7 & 13.1 & \\
\hline Skilled attendant at delivery & & & & 0.92 & & & & 0.85 \\
\hline Other (incl. none) & 56.7 & 58.6 & 57.6 & & 42.9 & 42.9 & 42.9 & \\
\hline Doctor, nurse, or midwife & 43.3 & 41.4 & 42.4 & & 57.1 & 57.1 & 57.1 & \\
\hline Type of gender preference & & & & $<0.001$ & & & & $<0.001$ \\
\hline No gender preference & 31.2 & 29.8 & 30.5 & & 24.3 & 25.0 & 24.7 & \\
\hline Balance preference & 30.7 & 29.4 & 30.1 & & 37.3 & 37.0 & 37.1 & \\
\hline Daughter preference & 17.2 & 12.8 & 15.1 & & 22.3 & 17.0 & 19.7 & \\
\hline Son preference & 20.9 & 28.0 & 24.4 & & 16.1 & 21.0 & 18.5 & \\
\hline Maternal education & & & & 0.81 & & & & 0.28 \\
\hline No education & 23.3 & 23.9 & 23.6 & & 64.1 & 63.7 & 63.9 & \\
\hline Primary & 42.6 & 41.1 & 41.9 & & 24.5 & 27.2 & 25.9 & \\
\hline Secondary or higher & 34.1 & 35.0 & 34.5 & & 11.4 & 9.1 & 10.2 & \\
\hline Household wealth Index & & & & 0.075 & & & & 0.007 \\
\hline 1st quintile (Poorest) & 21.3 & 20.5 & 20.9 & & 23.2 & 23.7 & 23.4 & \\
\hline 2nd quintile & 23.5 & 21.1 & 22.3 & & 21.7 & 20.8 & 21.2 & \\
\hline 3rd quintile & 20.0 & 22.1 & 21.0 & & 23.2 & 20.1 & 21.7 & \\
\hline 4th quintile & 19.5 & 21.3 & 20.4 & & 16.4 & 20.8 & 18.6 & \\
\hline 5th quintile (Richest) & 15.7 & 15.0 & 15.3 & & 15.5 & 14.7 & 15.1 & \\
\hline Urban-rural area of residence & & & & 0.28 & & & & 0.89 \\
\hline Rural & 61.5 & 60.4 & 61.0 & & 62.0 & 62.5 & 62.2 & \\
\hline Urban & 38.5 & 39.6 & 39.0 & & 38.0 & 37.5 & 37.8 & \\
\hline Women with secondary or higher (\%) & & & & 0.59 & & & & 0.93 \\
\hline Low & 45.3 & 45.7 & 45.5 & & 47.6 & 48.5 & 48.1 & \\
\hline High & 54.7 & 54.3 & 54.5 & & 52.4 & 51.5 & 51.9 & \\
\hline Women birthing in a health facility (\%) & & & & 0.71 & & & & 0.45 \\
\hline Low & 49.6 & 49.6 & 49.6 & & 48.0 & 48.0 & 48.0 & \\
\hline High & 50.4 & 50.4 & 50.4 & & 52.0 & 52.0 & 52.0 & \\
\hline Women who have a son preference $(\%)$ & & & & 0.065 & & & & 0.60 \\
\hline Low & 47.6 & 46.4 & 47.0 & & 50.8 & 51.5 & 51.2 & \\
\hline High & 52.4 & 53.6 & 53.0 & & 49.2 & 48.5 & 48.8 & \\
\hline Mean wealth index quintile score & & & & 0.25 & & & & 0.86 \\
\hline Low & 51.3 & 51.2 & 51.2 & & 51.4 & 51.6 & 51.5 & \\
\hline High & 48.7 & 48.8 & 48.8 & & 48.6 & 48.4 & 48.5 & \\
\hline Number of children (N: weighted) & 4423 & 4266 & 8689 & & 3565 & 3575 & 7141 & \\
\hline
\end{tabular}




\section{Appendix Table 3 (cont'd).}

\begin{tabular}{|c|c|c|c|c|c|c|c|c|}
\hline \multirow[t]{2}{*}{ Variables } & \multirow{2}{*}{$\begin{array}{c}\text { Ethiopia } \\
\text { Female } \\
(\%)\end{array}$} & \multicolumn{7}{|c|}{ Gabon } \\
\hline & & $\begin{array}{c}\text { Male } \\
(\%)\end{array}$ & $\begin{array}{c}\text { Total } \\
(\%)\end{array}$ & p-values & $\begin{array}{c}\text { Female } \\
(\%)\end{array}$ & $\begin{array}{c}\text { Male } \\
(\%)\end{array}$ & $\begin{array}{c}\text { Total } \\
(\%)\end{array}$ & p-values \\
\hline Child size at birth & & & & $<0.001$ & & & & $<0.001$ \\
\hline Average or larger than average & 67.1 & 74.6 & 71.0 & & 81.2 & 85.5 & 83.5 & \\
\hline Very small and smaller than average & 32.9 & 25.4 & 29.0 & & 18.8 & 14.5 & 16.5 & \\
\hline Birth order and preceding birth interval & & & & 0.064 & & & & 0.20 \\
\hline First birth & 19.1 & 19.7 & 19.4 & & 29.4 & 29.1 & 29.3 & \\
\hline $2-3$ and $<24$ months & 6.3 & 7.3 & 6.8 & & 7.2 & 6.7 & 6.9 & \\
\hline $2-3$ and $24+$ months & 26.0 & 22.9 & 24.4 & & 30.2 & 32.7 & 31.5 & \\
\hline $4+$ and $<24$ months & 9.3 & 10.0 & 9.6 & & 6.6 & 5.9 & 6.3 & \\
\hline $4+$ and $24+$ months & 39.4 & 40.1 & 39.8 & & 26.6 & 25.6 & 26.1 & \\
\hline Mother's age at child birth & & & & 0.093 & & & & 0.19 \\
\hline Less than 20 years & 13.3 & 13.0 & 13.1 & & 23.9 & 18.1 & 20.9 & \\
\hline $20-34$ years & 73.0 & 72.9 & 72.9 & & 63.5 & 69.6 & 66.6 & \\
\hline Greater than 35 years & 13.7 & 14.2 & 14.0 & & 12.7 & 12.3 & 12.5 & \\
\hline Skilled attendant at delivery & & & & 0.90 & & & & 0.78 \\
\hline Other (incl. none) & 89.9 & 90.2 & 90.0 & & 82.0 & 82.2 & 82.1 & \\
\hline Doctor, nurse, or midwife & 10.1 & 9.8 & 10.0 & & 18.0 & 17.8 & 17.9 & \\
\hline Type of gender preference & & & & $<0.001$ & & & & $<0.001$ \\
\hline No gender preference & 27.6 & 29.3 & 28.5 & & 14.6 & 16.1 & 15.4 & \\
\hline Balance preference & 48.8 & 44.7 & 46.7 & & 50.2 & 47.0 & 48.6 & \\
\hline Daughter preference & 7.5 & 4.5 & 6.0 & & 25.4 & 19.5 & 22.3 & \\
\hline Son preference & 16.0 & 21.4 & 18.8 & & 9.8 & 17.4 & 13.7 & \\
\hline Maternal education & & & & 0.50 & & & & 0.49 \\
\hline No education & 69.4 & 69.3 & 69.3 & & 6.1 & 7.1 & 6.6 & \\
\hline Primary & 26.6 & 27.5 & 27.1 & & 27.5 & 25.4 & 26.4 & \\
\hline Secondary or higher & 4.0 & 3.3 & 3.6 & & 66.4 & 67.5 & 67.0 & \\
\hline Household wealth Index & & & & 0.52 & & & & 0.39 \\
\hline 1st quintile (Poorest) & 23.1 & 22.4 & 22.7 & & 21.9 & 20.7 & 21.3 & \\
\hline 2nd quintile & 22.5 & 22.6 & 22.6 & & 23.5 & 22.0 & 22.7 & \\
\hline 3rd quintile & 20.1 & 21.2 & 20.7 & & 21.9 & 20.0 & 20.9 & \\
\hline 4 th quintile & 18.7 & 19.1 & 18.9 & & 17.1 & 20.7 & 18.9 & \\
\hline 5th quintile (Richest) & 15.5 & 14.7 & 15.1 & & 15.6 & 16.8 & 16.2 & \\
\hline Urban-rural area of residence & & & & 0.50 & & & & 0.052 \\
\hline Rural & 87.0 & 87.2 & 87.1 & & 16.9 & 14.5 & 15.7 & \\
\hline Urban & 13.0 & 12.8 & 12.9 & & 83.1 & 85.5 & 84.3 & \\
\hline Women with secondary or higher $(\%)$ & & & & 0.65 & & & & 0.23 \\
\hline Low & 76.3 & 77.6 & 77.0 & & 25.5 & 24.2 & 24.8 & \\
\hline High & 23.7 & 22.4 & 23.0 & & 74.5 & 75.8 & 75.2 & \\
\hline Women birthing in a health facility $(\%)$ & & & & 0.54 & & & & 0.37 \\
\hline Low & 54.6 & 56.5 & 55.6 & & 29.4 & 28.0 & 28.7 & \\
\hline High & 45.4 & 43.5 & 44.4 & & 70.6 & 72.0 & 71.3 & \\
\hline Women who have a son preference $(\%)$ & & & & 0.15 & & & & 0.047 \\
\hline Low & 54.2 & 54.3 & 54.2 & & 47.9 & 41.1 & 44.4 & \\
\hline High & 45.8 & 45.7 & 45.8 & & 52.1 & 58.9 & 55.6 & \\
\hline Mean wealth index quintile score & & & & 0.10 & & & & 0.059 \\
\hline Low & 45.6 & 46.1 & 45.9 & & 21.9 & 19.5 & 20.6 & \\
\hline High & 54.4 & 53.9 & 54.1 & & 78.1 & 80.5 & 79.4 & \\
\hline Number of children (N: weighted) & 5558 & 6040 & 11597 & & 2376 & 2532 & 4908 & \\
\hline
\end{tabular}


Appendix Table 3 (cont'd).

\begin{tabular}{|c|c|c|c|c|c|c|c|c|}
\hline \multirow[t]{2}{*}{ Variables } & \multirow{2}{*}{$\begin{array}{l}\text { Ghana } \\
\text { Female } \\
(\%)\end{array}$} & \multicolumn{7}{|c|}{ Guinea } \\
\hline & & $\begin{array}{c}\text { Male } \\
(\%)\end{array}$ & $\begin{array}{c}\text { Total } \\
(\%)\end{array}$ & p-values & $\begin{array}{c}\text { Female } \\
(\%)\end{array}$ & $\begin{array}{c}\text { Male } \\
(\%)\end{array}$ & $\begin{array}{c}\text { Total } \\
(\%)\end{array}$ & p-values \\
\hline Child size at birth & & & & $<0.001$ & & & & $<0.001$ \\
\hline Average or larger than average & 84.7 & 89.1 & 87.0 & & 84.1 & 87.4 & 85.8 & \\
\hline Very small and smaller than average & 15.3 & 10.9 & 13.0 & & 15.9 & 12.6 & 14.2 & \\
\hline Birth order and preceding birth interval & & & & 0.11 & & & & 0.45 \\
\hline First birth & 25.3 & 23.9 & 24.6 & & 17.8 & 18.0 & 17.9 & \\
\hline $2-3$ and $<24$ months & 5.9 & 5.2 & 5.5 & & 3.8 & 3.0 & 3.4 & \\
\hline $2-3$ and $24+$ months & 30.4 & 35.2 & 32.8 & & 27.2 & 28.5 & 27.9 & \\
\hline $4+$ and $<24$ months & 5.9 & 4.6 & 5.2 & & 5.6 & 6.2 & 5.9 & \\
\hline $4+$ and $24+$ months & 32.5 & 31.2 & 31.8 & & 45.7 & 44.2 & 44.9 & \\
\hline Mother's age at child birth & & & & 0.42 & & & & 0.22 \\
\hline Less than 20 years & 12.2 & 11.8 & 12.0 & & 19.0 & 17.8 & 18.3 & \\
\hline 20-34 years & 70.6 & 72.5 & 71.6 & & 63.1 & 65.6 & 64.4 & \\
\hline Greater than 35 years & 17.2 & 15.7 & 16.5 & & 17.9 & 16.7 & 17.3 & \\
\hline Skilled attendant at delivery & & & & 0.63 & & & & 0.012 \\
\hline Other (incl. none) & 46.6 & 44.8 & 45.7 & & 73.2 & 70.1 & 71.6 & \\
\hline Doctor, nurse, or midwife & 53.4 & 55.2 & 54.3 & & 26.8 & 29.9 & 28.4 & \\
\hline Type of gender preference & & & & $<0.001$ & & & & 0.005 \\
\hline No gender preference & 16.4 & 13.9 & 15.1 & & 26.4 & 28.0 & 27.3 & \\
\hline Balance preference & 46.2 & 46.3 & 46.3 & & 38.7 & 38.6 & 38.6 & \\
\hline Daughter preference & 22.9 & 15.3 & 19.0 & & 10.9 & 8.3 & 9.5 & \\
\hline Son preference & 14.5 & 24.5 & 19.6 & & 24.0 & 25.1 & 24.6 & \\
\hline Maternal education & & & & 0.85 & & & & 0.45 \\
\hline No education & 32.4 & 32.9 & 32.6 & & 87.5 & 86.0 & 86.7 & \\
\hline Primary & 24.2 & 25.3 & 24.7 & & 7.9 & 8.8 & 8.4 & \\
\hline Secondary or higher & 43.4 & 41.9 & 42.6 & & 4.6 & 5.2 & 4.9 & \\
\hline Household wealth Index & & & & 0.38 & & & & 0.77 \\
\hline 1st quintile (Poorest) & 25.5 & 25.6 & 25.6 & & 25.2 & 24.0 & 24.6 & \\
\hline 2nd quintile & 23.4 & 21.2 & 22.2 & & 21.3 & 21.6 & 21.5 & \\
\hline 3rd quintile & 17.4 & 19.8 & 18.6 & & 21.3 & 20.7 & 21.0 & \\
\hline 4th quintile & 20.6 & 18.6 & 19.6 & & 17.6 & 18.3 & 18.0 & \\
\hline 5th quintile (Richest) & 13.2 & 14.8 & 14.0 & & 14.5 & 15.3 & 14.9 & \\
\hline Urban-rural area of residence & & & & 0.91 & & & & 0.13 \\
\hline Rural & 62.4 & 62.4 & 62.4 & & 78.5 & 76.5 & 77.5 & \\
\hline Urban & 37.6 & 37.6 & 37.6 & & 21.5 & 23.5 & 22.5 & \\
\hline Women with secondary or higher (\%) & & & & 0.17 & & & & 0.15 \\
\hline Low & 43.6 & 47.7 & 45.7 & & 66.5 & 64.7 & 65.5 & \\
\hline High & 56.4 & 52.3 & 54.3 & & 33.5 & 35.3 & 34.5 & \\
\hline Women birthing in a health facility (\%) & & & & 0.68 & & & & 0.25 \\
\hline Low & 46.4 & 45.6 & 46.0 & & 50.4 & 49.0 & 49.6 & \\
\hline High & 53.6 & 54.4 & 54.0 & & 49.6 & 51.0 & 50.4 & \\
\hline Women who have a son preference (\%) & & & & 0.019 & & & & 0.84 \\
\hline Low & 58.9 & 54.6 & 56.7 & & 50.8 & 50.3 & 50.5 & \\
\hline High & 41.1 & 45.4 & 43.3 & & 49.2 & 49.7 & 49.5 & \\
\hline Mean wealth index quintile score & & & & 0.41 & & & & 0.38 \\
\hline Low & 42.9 & 41.4 & 42.1 & & 49.4 & 48.1 & 48.8 & \\
\hline High & 57.1 & 58.6 & 57.9 & & 50.6 & 51.9 & 51.2 & \\
\hline Number of children (N: weighted) & 1345 & 1438 & 2783 & & 2904 & 3130 & 6034 & \\
\hline
\end{tabular}


Appendix Table 3 (cont'd).

\begin{tabular}{|c|c|c|c|c|c|c|c|c|}
\hline \multirow[t]{2}{*}{ Variables } & \multirow{2}{*}{$\begin{array}{l}\text { Kenya } \\
\text { Female } \\
(\%)\end{array}$} & \multicolumn{7}{|c|}{ Lesotho } \\
\hline & & $\begin{array}{c}\text { Male } \\
(\%)\end{array}$ & $\begin{array}{c}\text { Total } \\
(\%)\end{array}$ & p-values & $\begin{array}{c}\text { Female } \\
(\%)\end{array}$ & $\begin{array}{c}\text { Male } \\
(\%)\end{array}$ & $\begin{array}{c}\text { Total } \\
(\%)\end{array}$ & p-values \\
\hline Child size at birth & & & & $<0.001$ & & & & 0.018 \\
\hline Average or larger than average & 82.0 & 86.6 & 84.4 & & 85.9 & 89.5 & 87.7 & \\
\hline Very small and smaller than average & 18.0 & 13.4 & 15.6 & & 14.1 & 10.5 & 12.3 & \\
\hline Birth order and preceding birth interval & & & & 0.50 & & & & 0.73 \\
\hline First birth & 23.7 & 22.0 & 22.8 & & 39.6 & 39.7 & 39.7 & \\
\hline $2-3$ and $<24$ months & 8.2 & 9.1 & 8.7 & & 5.0 & 5.5 & 5.2 & \\
\hline $2-3$ and $24+$ months & 29.5 & 29.8 & 29.7 & & 34.2 & 33.4 & 33.8 & \\
\hline $4+$ and $<24$ months & 8.2 & 9.8 & 9.0 & & 1.9 & 2.5 & 2.2 & \\
\hline $4+$ and $24+$ months & 30.4 & 29.3 & 29.8 & & 19.2 & 19.0 & 19.1 & \\
\hline Mother's age at child birth & & & & 0.35 & & & & 0.57 \\
\hline Less than 20 years & 17.6 & 15.6 & 16.6 & & 21.9 & 21.3 & 21.6 & \\
\hline $20-34$ years & 71.0 & 73.9 & 72.5 & & 67.2 & 67.5 & 67.3 & \\
\hline Greater than 35 years & 11.4 & 10.5 & 10.9 & & 10.9 & 11.2 & 11.1 & \\
\hline Skilled attendant at delivery & & & & 0.31 & & & & 0.46 \\
\hline Other (incl. none) & 56.8 & 56.1 & 56.4 & & 38.1 & 38.4 & 38.2 & \\
\hline Doctor, nurse, or midwife & 43.2 & 43.9 & 43.6 & & 61.9 & 61.6 & 61.8 & \\
\hline Type of gender preference & & & & $<0.001$ & & & & $<0.001$ \\
\hline No gender preference & 25.7 & 27.6 & 26.7 & & 9.7 & 9.4 & 9.5 & \\
\hline Balance preference & 46.2 & 45.1 & 45.6 & & 54.9 & 53.1 & 54.0 & \\
\hline Daughter preference & 14.6 & 9.3 & 11.9 & & 17.7 & 13.7 & 15.6 & \\
\hline Son preference & 13.5 & 17.9 & 15.8 & & 17.7 & 23.8 & 20.8 & \\
\hline Maternal education & & & & 0.67 & & & & 0.81 \\
\hline No education & 12.6 & 13.3 & 13.0 & & 1.8 & 1.6 & 1.7 & \\
\hline Primary & 63.4 & 64.1 & 63.8 & & 56.7 & 55.9 & 56.3 & \\
\hline Secondary or higher & 24.1 & 22.6 & 23.3 & & 41.5 & 42.4 & 42.0 & \\
\hline Household wealth Index & & & & 0.96 & & & & 0.25 \\
\hline 1st quintile (Poorest) & 24.6 & 24.7 & 24.7 & & 21.6 & 23.8 & 22.7 & \\
\hline 2nd quintile & 20.0 & 20.8 & 20.4 & & 21.6 & 18.1 & 19.8 & \\
\hline 3rd quintile & 18.6 & 18.1 & 18.3 & & 17.8 & 19.1 & 18.5 & \\
\hline 4th quintile & 17.9 & 17.7 & 17.8 & & 21.2 & 21.3 & 21.3 & \\
\hline 5th quintile (Richest) & 18.9 & 18.8 & 18.8 & & 17.8 & 17.7 & 17.8 & \\
\hline Urban-rural area of residence & & & & 0.63 & & & & 0.025 \\
\hline Rural & 81.6 & 81.7 & 81.7 & & 75.7 & 77.8 & 76.7 & \\
\hline Urban & 18.4 & 18.3 & 18.3 & & 24.3 & 22.2 & 23.3 & \\
\hline Women with secondary or higher (\%) & & & & 0.84 & & & & 0.76 \\
\hline Low & 45.2 & 44.3 & 44.7 & & 44.3 & 44.0 & 44.2 & \\
\hline High & 54.8 & 55.7 & 55.3 & & 55.7 & 56.0 & 55.8 & \\
\hline Women birthing in a health facility (\%) & & & & 0.80 & & & & 0.82 \\
\hline Low & 49.4 & 47.3 & 48.3 & & 43.6 & 45.3 & 44.5 & \\
\hline High & 50.6 & 52.7 & 51.7 & & 56.4 & 54.7 & 55.5 & \\
\hline Women who have a son preference $(\%)$ & & & & 0.084 & & & & 0.036 \\
\hline Low & 53.6 & 51.5 & 52.5 & & 52.5 & 49.5 & 51.0 & \\
\hline High & 46.4 & 48.5 & 47.5 & & 47.5 & 50.5 & 49.0 & \\
\hline Mean wealth index quintile score & & & & 0.47 & & & & 0.72 \\
\hline Low & 48.1 & 49.7 & 48.9 & & 38.0 & 39.5 & 38.7 & \\
\hline High & 51.9 & 50.3 & 51.1 & & 62.0 & 60.5 & 61.3 & \\
\hline Number of children (N: weighted) & 2751 & 2947 & 5698 & & 1772 & 1844 & 3616 & \\
\hline
\end{tabular}


Appendix Table 3 (cont'd).

\begin{tabular}{|c|c|c|c|c|c|c|c|c|}
\hline \multirow[t]{2}{*}{ Variables } & \multicolumn{2}{|l|}{ Liberia } & \multicolumn{6}{|c|}{ Madagascar } \\
\hline & $\begin{array}{c}\text { Female } \\
(\%)\end{array}$ & $\begin{array}{l}\text { Male } \\
(\%)\end{array}$ & $\begin{array}{c}\text { Total } \\
(\%)\end{array}$ & $\mathrm{p}$-values & $\begin{array}{c}\text { Female } \\
(\%)\end{array}$ & $\begin{array}{c}\text { Male } \\
(\%)\end{array}$ & $\begin{array}{c}\text { Total } \\
(\%)\end{array}$ & p-values \\
\hline Child size at birth & & & & $<0.001$ & & & & $<0.001$ \\
\hline Average or larger than average & 74.5 & 79.7 & 77.2 & & 78.0 & 83.2 & 80.7 & \\
\hline Very small and smaller than average & 25.5 & 20.3 & 22.8 & & 22.0 & 16.8 & 19.3 & \\
\hline Birth order and preceding birth interval & & & & 0.32 & & & & 0.81 \\
\hline First birth & 23.0 & 23.8 & 23.4 & & 23.1 & 22.3 & 22.7 & \\
\hline $2-3$ and $<24$ months & 6.1 & 5.9 & 6.0 & & 7.8 & 7.7 & 7.7 & \\
\hline $2-3$ and $24+$ months & 29.9 & 26.5 & 28.1 & & 27.0 & 26.6 & 26.8 & \\
\hline $4+$ and $<24$ months & 7.3 & 8.4 & 7.8 & & 10.0 & 10.0 & 10.0 & \\
\hline $4+$ and $24+$ months & 33.8 & 35.5 & 34.7 & & 32.2 & 33.3 & 32.7 & \\
\hline Mother's age at child birth & & & & 0.12 & & & & 0.93 \\
\hline Less than 20 years & 17.9 & 17.2 & 17.5 & & 21.1 & 21.4 & 21.3 & \\
\hline 20-34 years & 67.2 & 65.2 & 66.2 & & 63.8 & 62.8 & 63.3 & \\
\hline Greater than 35 years & 15.0 & 17.6 & 16.3 & & 15.1 & 15.8 & 15.4 & \\
\hline Skilled attendant at delivery & & & & 0.48 & & & & 0.85 \\
\hline Other (incl. none) & 54.5 & 53.8 & 54.1 & & 56.0 & 56.2 & 56.1 & \\
\hline Doctor, nurse, or midwife & 45.5 & 46.2 & 45.9 & & 44.0 & 43.8 & 43.9 & \\
\hline Type of gender preference & & & & $<0.001$ & & & & $<0.001$ \\
\hline No gender preference & 13.4 & 13.4 & 13.4 & & 11.0 & 10.3 & 10.6 & \\
\hline Balance preference & 48.4 & 46.6 & 47.5 & & 62.0 & 64.1 & 63.0 & \\
\hline Daughter preference & 22.8 & 18.0 & 20.3 & & 13.1 & 8.0 & 10.5 & \\
\hline Son preference & 15.3 & 22.1 & 18.9 & & 13.9 & 17.7 & 15.9 & \\
\hline Maternal education & & & & 0.095 & & & & 0.51 \\
\hline No education & 46.7 & 50.9 & 48.9 & & 25.0 & 25.8 & 25.4 & \\
\hline Primary & 36.5 & 33.2 & 34.8 & & 56.0 & 54.7 & 55.3 & \\
\hline Secondary or higher & 16.8 & 15.9 & 16.3 & & 19.1 & 19.5 & 19.3 & \\
\hline Household wealth Index & & & & 0.11 & & & & 0.036 \\
\hline 1st quintile (Poorest) & 22.0 & 22.6 & 22.3 & & 24.6 & 27.0 & 25.8 & \\
\hline 2nd quintile & 24.6 & 22.8 & 23.6 & & 23.0 & 21.7 & 22.4 & \\
\hline 3rd quintile & 20.8 & 22.3 & 21.5 & & 20.3 & 19.8 & 20.1 & \\
\hline 4th quintile & 21.2 & 19.3 & 20.2 & & 17.9 & 17.6 & 17.7 & \\
\hline 5th quintile (Richest) & 11.3 & 13.1 & 12.3 & & 14.2 & 13.9 & 14.0 & \\
\hline Urban-rural area of residence & & & & 0.45 & & & & 0.91 \\
\hline Rural & 68.7 & 70.3 & 69.5 & & 89.4 & 89.0 & 89.2 & \\
\hline Urban & 31.3 & 29.7 & 30.5 & & 10.6 & 11.0 & 10.8 & \\
\hline Women with secondary or higher (\%) & & & & 0.50 & & & & 0.078 \\
\hline Low & 51.3 & 52.8 & 52.0 & & 50.2 & 48.5 & 49.3 & \\
\hline High & 48.7 & 47.2 & 48.0 & & 49.8 & 51.5 & 50.7 & \\
\hline Women birthing in a health facility (\%) & & & & 0.29 & & & & 0.90 \\
\hline Low & 49.6 & 51.7 & 50.7 & & 50.0 & 50.8 & 50.4 & \\
\hline High & 50.4 & 48.3 & 49.3 & & 50.0 & 49.2 & 49.6 & \\
\hline Women who have a son preference (\%) & & & & 0.002 & & & & 0.20 \\
\hline Low & 50.6 & 45.9 & 48.1 & & 50.5 & 50.4 & 50.5 & \\
\hline High & 49.4 & 54.1 & 51.9 & & 49.5 & 49.6 & 49.5 & \\
\hline Mean wealth index quintile score & & & & 0.96 & & & & 0.94 \\
\hline Low & 50.4 & 49.7 & 50.0 & & 46.9 & 47.4 & 47.2 & \\
\hline High & 49.6 & 50.3 & 50.0 & & 53.1 & 52.6 & 52.8 & \\
\hline Number of children (N: weighted) & 2580 & 2792 & 5372 & & 6101 & 6348 & 12449 & \\
\hline
\end{tabular}




\section{Appendix Table 3 (cont'd).}

\begin{tabular}{|c|c|c|c|c|c|c|c|c|}
\hline \multirow[t]{2}{*}{ Variables } & \multirow{2}{*}{$\begin{array}{c}\text { Malawi } \\
\text { Female } \\
(\%)\end{array}$} & \multicolumn{7}{|c|}{ Mali } \\
\hline & & $\begin{array}{c}\text { Male } \\
(\%)\end{array}$ & $\begin{array}{c}\text { Total } \\
(\%)\end{array}$ & p-values & $\begin{array}{c}\text { Female } \\
(\%)\end{array}$ & $\begin{array}{c}\text { Male } \\
(\%)\end{array}$ & $\begin{array}{c}\text { Total } \\
(\%)\end{array}$ & p-values \\
\hline Child size at birth & & & & $<0.001$ & & & & $<0.001$ \\
\hline Average or larger than average & 83.8 & 87.0 & 85.4 & & 78.3 & 84.2 & 81.3 & \\
\hline Very small and smaller than average & 16.2 & 13.0 & 14.6 & & 21.7 & 15.8 & 18.7 & \\
\hline Birth order and preceding birth interval & & & & 0.88 & & & & 0.14 \\
\hline First birth & 20.8 & 21.8 & 21.3 & & 17.7 & 18.4 & 18.1 & \\
\hline $2-3$ and $<24$ months & 5.5 & 5.8 & 5.7 & & 6.9 & 7.2 & 7.1 & \\
\hline $2-3$ and $24+$ months & 31.2 & 31.2 & 31.2 & & 24.1 & 23.6 & 23.9 & \\
\hline $4+$ and $<24$ months & 6.4 & 6.2 & 6.3 & & 11.0 & 10.7 & 10.9 & \\
\hline $4+$ and $24+$ months & 36.1 & 35.0 & 35.6 & & 40.3 & 40.0 & 40.2 & \\
\hline Mother's age at child birth & & & & 0.10 & & & & 0.45 \\
\hline Less than 20 years & 18.4 & 18.9 & 18.6 & & 20.2 & 20.7 & 20.5 & \\
\hline $20-34$ years & 69.0 & 69.2 & 69.1 & & 65.8 & 65.2 & 65.5 & \\
\hline Greater than 35 years & 12.6 & 11.8 & 12.2 & & 14.0 & 14.1 & 14.0 & \\
\hline Skilled attendant at delivery & & & & 0.072 & & & & 0.44 \\
\hline Other (incl. none) & 29.3 & 27.7 & 28.5 & & 74.1 & 72.4 & 73.2 & \\
\hline Doctor, nurse, or midwife & 70.7 & 72.3 & 71.5 & & 25.9 & 27.6 & 26.8 & \\
\hline Type of gender preference & & & & $<0.001$ & & & & $<0.001$ \\
\hline No gender preference & 11.3 & 10.5 & 10.9 & & 25.3 & 24.8 & 25.1 & \\
\hline Balance preference & 54.7 & 54.1 & 54.4 & & 35.9 & 36.0 & 35.9 & \\
\hline Daughter preference & 24.1 & 17.4 & 20.8 & & 11.7 & 7.5 & 9.6 & \\
\hline Son preference & 9.9 & 18.1 & 14.0 & & 27.1 & 31.7 & 29.4 & \\
\hline Maternal education & & & & 0.92 & & & & 0.23 \\
\hline No education & 17.4 & 17.5 & 17.5 & & 85.0 & 86.0 & 85.5 & \\
\hline Primary & 68.2 & 67.6 & 67.9 & & 10.3 & 9.9 & 10.1 & \\
\hline Secondary or higher & 14.4 & 14.9 & 14.6 & & 4.7 & 4.2 & 4.4 & \\
\hline Household wealth Index & & & & 0.047 & & & & 0.14 \\
\hline 1st quintile (Poorest) & 21.3 & 22.0 & 21.6 & & 20.5 & 20.4 & 20.5 & \\
\hline 2nd quintile & 21.7 & 22.4 & 22.0 & & 20.6 & 20.3 & 20.5 & \\
\hline 3rd quintile & 22.4 & 20.9 & 21.6 & & 20.6 & 21.4 & 21.0 & \\
\hline 4th quintile & 18.9 & 17.9 & 18.4 & & 20.8 & 20.2 & 20.5 & \\
\hline 5th quintile (Richest) & 15.7 & 16.9 & 16.3 & & 17.5 & 17.6 & 17.6 & \\
\hline Urban-rural area of residence & & & & 0.28 & & & & 0.49 \\
\hline Rural & 85.8 & 85.6 & 85.7 & & 73.0 & 72.6 & 72.8 & \\
\hline Urban & 14.2 & 14.4 & 14.3 & & 27.0 & 27.4 & 27.2 & \\
\hline Women with secondary or higher $(\%)$ & & & & 0.30 & & & & 0.74 \\
\hline Low & 49.3 & 48.3 & 48.8 & & 60.8 & 61.0 & 60.9 & \\
\hline High & 50.7 & 51.7 & 51.2 & & 39.2 & 39.0 & 39.1 & \\
\hline Women birthing in a health facility $(\%)$ & & & & 0.79 & & & & 0.16 \\
\hline Low & 49.1 & 48.6 & 48.9 & & 48.7 & 49.2 & 48.9 & \\
\hline High & 50.9 & 51.4 & 51.1 & & 51.3 & 50.8 & 51.1 & \\
\hline Women who have a son preference $(\%)$ & & & & 0.007 & & & & 0.10 \\
\hline Low & 50.7 & 47.6 & 49.1 & & 49.8 & 48.2 & 49.0 & \\
\hline High & 49.3 & 52.4 & 50.9 & & 50.2 & 51.8 & 51.0 & \\
\hline Mean wealth index quintile score & & & & 0.57 & & & & 0.18 \\
\hline Low & 48.6 & 49.1 & 48.9 & & 51.3 & 51.7 & 51.5 & \\
\hline High & 51.4 & 50.9 & 51.1 & & 48.7 & 48.3 & 48.5 & \\
\hline Number of children (N: weighted) & 9454 & 9396 & 18850 & & 6886 & 7055 & 13941 & \\
\hline
\end{tabular}


Appendix Table 3 (cont'd).

\begin{tabular}{|c|c|c|c|c|c|c|c|c|}
\hline \multirow[t]{2}{*}{ Variables } & \multicolumn{2}{|c|}{ Mozambique } & \multicolumn{5}{|c|}{ Namibia } & \multirow[b]{2}{*}{ p-values } \\
\hline & $\begin{array}{c}\text { Female } \\
(\%)\end{array}$ & $\begin{array}{c}\text { Male } \\
(\%)\end{array}$ & $\begin{array}{c}\text { Total } \\
(\%)\end{array}$ & p-values & $\begin{array}{c}\text { Female } \\
(\%)\end{array}$ & $\begin{array}{c}\text { Male } \\
(\%)\end{array}$ & $\begin{array}{c}\text { Total } \\
(\%)\end{array}$ & \\
\hline Child size at birth & & & & $<0.001$ & & & & 0.003 \\
\hline Average or larger than average & 86.0 & 88.5 & 87.3 & & 83.5 & 85.9 & 84.7 & \\
\hline Very small and smaller than average & 14.0 & 11.5 & 12.7 & & 16.5 & 14.1 & 15.3 & \\
\hline Birth order and preceding birth interval & & & & 0.38 & & & & 0.83 \\
\hline First birth & 22.5 & 22.2 & 22.4 & & 32.7 & 32.9 & 32.8 & \\
\hline $2-3$ and $<24$ months & 4.7 & 4.3 & 4.5 & & 5.6 & 5.5 & 5.6 & \\
\hline $2-3$ and $24+$ months & 28.9 & 30.8 & 29.9 & & 35.3 & 36.5 & 35.9 & \\
\hline $4+$ and $<24$ months & 6.6 & 6.8 & 6.7 & & 3.8 & 3.5 & 3.7 & \\
\hline $4+$ and $24+$ months & 37.2 & 35.9 & 36.6 & & 22.5 & 21.5 & 22.0 & \\
\hline Mother's age at child birth & & & & 0.42 & & & & 0.74 \\
\hline Less than 20 years & 20.6 & 19.8 & 20.2 & & 16.1 & 16.3 & 16.2 & \\
\hline 20-34 years & 64.9 & 65.2 & 65.1 & & 70.1 & 69.3 & 69.7 & \\
\hline Greater than 35 years & 14.5 & 14.9 & 14.7 & & 13.8 & 14.5 & 14.1 & \\
\hline Skilled attendant at delivery & & & & 0.057 & & & & 0.14 \\
\hline Other (incl. none) & 82.4 & 80.8 & 81.6 & & 19.1 & 17.9 & 18.5 & \\
\hline Doctor, nurse, or midwife & 17.6 & 19.2 & 18.4 & & 80.9 & 82.1 & 81.5 & \\
\hline Type of gender preference & & & & $<0.001$ & & & & $<0.001$ \\
\hline No gender preference & 8.6 & 8.8 & 8.7 & & 13.6 & 12.9 & 13.2 & \\
\hline Balance preference & 57.1 & 56.1 & 56.6 & & 48.6 & 50.6 & 49.6 & \\
\hline Daughter preference & 18.8 & 16.5 & 17.6 & & 26.4 & 18.2 & 22.2 & \\
\hline Son preference & 15.4 & 18.7 & 17.1 & & 11.5 & 18.2 & 14.9 & \\
\hline Maternal education & & & & 0.22 & & & & 0.53 \\
\hline No education & 36.9 & 36.7 & 36.8 & & 11.1 & 11.0 & 11.0 & \\
\hline Primary & 52.4 & 51.4 & 51.9 & & 28.7 & 28.5 & 28.6 & \\
\hline Secondary or higher & 10.7 & 11.9 & 11.3 & & 60.2 & 60.5 & 60.4 & \\
\hline Household wealth Index & & & & 0.16 & & & & 0.37 \\
\hline 1st quintile (Poorest) & 24.9 & 22.4 & 23.7 & & 21.7 & 20.9 & 21.3 & \\
\hline 2nd quintile & 21.1 & 21.8 & 21.4 & & 18.4 & 19.7 & 19.1 & \\
\hline 3rd quintile & 19.9 & 20.3 & 20.1 & & 22.2 & 22.7 & 22.5 & \\
\hline 4th quintile & 19.3 & 19.8 & 19.5 & & 21.1 & 20.9 & 21.0 & \\
\hline 5th quintile (Richest) & 14.7 & 15.7 & 15.3 & & 16.6 & 15.7 & 16.2 & \\
\hline Urban-rural area of residence & & & & 0.21 & & & & 0.65 \\
\hline Rural & 73.0 & 71.8 & 72.4 & & 57.3 & 59.3 & 58.3 & \\
\hline Urban & 27.0 & 28.2 & 27.6 & & 42.7 & 40.7 & 41.7 & \\
\hline Women with secondary or higher (\%) & & & & 0.91 & & & & 0.21 \\
\hline Low & 59.1 & 57.9 & 58.5 & & 47.3 & 46.8 & 47.1 & \\
\hline High & 40.9 & 42.1 & 41.5 & & 52.7 & 53.2 & 52.9 & \\
\hline Women birthing in a health facility (\%) & & & & 0.43 & & & & 0.43 \\
\hline Low & 58.2 & 57.5 & 57.8 & & 48.3 & 48.2 & 48.3 & \\
\hline High & 41.8 & 42.5 & 42.2 & & 51.7 & 51.8 & 51.7 & \\
\hline Women who have a son preference (\%) & & & & 0.81 & & & & 0.16 \\
\hline Low & 50.4 & 50.8 & 50.6 & & 54.0 & 51.2 & 52.6 & \\
\hline High & 49.6 & 49.2 & 49.4 & & 46.0 & 48.8 & 47.4 & \\
\hline Mean wealth index quintile score & & & & 0.27 & & & & 0.82 \\
\hline Low & 61.0 & 59.5 & 60.2 & & 50.4 & 50.5 & 50.4 & \\
\hline High & 39.0 & 40.5 & 39.8 & & 49.6 & 49.5 & 49.6 & \\
\hline Number of children (N: weighted) & 5554 & 5711 & 11265 & & 2363 & 2469 & 4832 & \\
\hline
\end{tabular}


Appendix Table 3 (cont'd).

\begin{tabular}{|c|c|c|c|c|c|c|c|c|}
\hline \multirow[t]{2}{*}{ Variables } & \multicolumn{4}{|l|}{ Niger } & \multicolumn{4}{|l|}{ Nigeria } \\
\hline & $\begin{array}{c}\text { Female } \\
(\%)\end{array}$ & $\begin{array}{c}\text { Male } \\
(\%)\end{array}$ & $\begin{array}{c}\text { Total } \\
(\%)\end{array}$ & p-values & $\begin{array}{c}\text { Female } \\
(\%)\end{array}$ & $\begin{array}{c}\text { Male } \\
(\%)\end{array}$ & $\begin{array}{c}\text { Total } \\
(\%)\end{array}$ & p-values \\
\hline Child size at birth & & & & $<0.001$ & & & & \\
\hline Average or larger than average & 75.1 & 79.1 & 77.2 & & 84.5 & 87.2 & 85.9 & $<0.001$ \\
\hline Very small and smaller than average & 24.9 & 20.9 & 22.8 & & 15.5 & 12.8 & 14.1 & \\
\hline Birth order and preceding birth interval & & & & 0.70 & & & & \\
\hline First birth & 16.0 & 15.9 & 16.0 & & 19.3 & 19.9 & 19.6 & 0.39 \\
\hline $2-3$ and $<24$ months & 6.9 & 5.7 & 6.3 & & 8.7 & 8.3 & 8.5 & \\
\hline $2-3$ and $24+$ months & 21.6 & 22.3 & 22.0 & & 24.7 & 25.4 & 25.0 & \\
\hline $4+$ and $<24$ months & 10.9 & 11.8 & 11.4 & & 10.8 & 10.8 & 10.8 & \\
\hline $4+$ and $24+$ months & 44.6 & 44.4 & 44.5 & & 36.4 & 35.7 & 36.1 & \\
\hline Mother's age at child birth & & & & 0.96 & & & & \\
\hline Less than 20 years & 18.9 & 18.9 & 18.9 & & 14.9 & 15.4 & 15.2 & 0.068 \\
\hline $20-34$ years & 66.9 & 66.8 & 66.8 & & 70.3 & 69.2 & 69.7 & \\
\hline Greater than 35 years & 14.3 & 14.3 & 14.3 & & 14.8 & 15.5 & 15.1 & \\
\hline Skilled attendant at delivery & & & & 0.93 & & & & \\
\hline Other (incl. none) & 82.4 & 82.7 & 82.5 & & 65.2 & 66.0 & 65.6 & 0.51 \\
\hline Doctor, nurse, or midwife & 17.6 & 17.3 & 17.5 & & 34.8 & 34.0 & 34.4 & \\
\hline Type of gender preference & & & & $<0.001$ & & & & \\
\hline No gender preference & 40.7 & 42.1 & 41.4 & & 33.7 & 34.6 & 34.2 & $<0.001$ \\
\hline Balance preference & 24.2 & 22.0 & 23.1 & & 36.0 & 35.0 & 35.5 & \\
\hline Daughter preference & 11.1 & 8.4 & 9.7 & & 9.8 & 7.2 & 8.4 & \\
\hline Son preference & 23.9 & 27.4 & 25.7 & & 20.5 & 23.2 & 21.9 & \\
\hline Maternal education & & & & 0.81 & & & & \\
\hline No education & 87.7 & 87.2 & 87.4 & & 46.5 & 47.0 & 46.7 & 0.43 \\
\hline Primary & 9.3 & 9.6 & 9.4 & & 23.3 & 22.8 & 23.0 & \\
\hline Secondary or higher & 3.0 & 3.2 & 3.1 & & 30.2 & 30.2 & 30.2 & \\
\hline Household wealth Index & & & & 0.30 & & & & \\
\hline 1st quintile (Poorest) & 20.6 & 22.6 & 21.6 & & 23.2 & 23.6 & 23.4 & 0.42 \\
\hline 2nd quintile & 20.6 & 19.3 & 19.9 & & 22.4 & 23.1 & 22.8 & \\
\hline 3rd quintile & 18.5 & 19.3 & 18.9 & & 19.3 & 19.0 & 19.1 & \\
\hline 4th quintile & 21.7 & 20.8 & 21.2 & & 17.6 & 17.9 & 17.7 & \\
\hline 5th quintile (Richest) & 18.6 & 18.0 & 18.3 & & 17.5 & 16.4 & 16.9 & \\
\hline Urban-rural area of residence & & & & 0.96 & & & & \\
\hline Rural & 84.6 & 85.1 & 84.9 & & 69.9 & 70.6 & 70.3 & 0.45 \\
\hline Urban & 15.4 & 14.9 & 15.1 & & 30.1 & 29.4 & 29.7 & \\
\hline Women with secondary or higher $(\%)$ & & & & 0.97 & & & & \\
\hline Low & 76.6 & 76.5 & 76.5 & & 46.2 & 46.6 & 46.4 & 0.84 \\
\hline High & 23.4 & 23.5 & 23.5 & & 53.8 & 53.4 & 53.6 & \\
\hline Women birthing in a health facility $(\%)$ & & & & 0.69 & & & & \\
\hline Low & 60.8 & 60.5 & 60.7 & & 45.8 & 46.6 & 46.2 & 0.25 \\
\hline High & 39.2 & 39.5 & 39.3 & & 54.2 & 53.4 & 53.8 & \\
\hline Women who have a son preference $(\%)$ & & & & 0.64 & & & & \\
\hline Low & 55.0 & 55.6 & 55.3 & & 51.9 & 50.5 & 51.2 & 0.062 \\
\hline High & 45.0 & 44.4 & 44.7 & & 48.1 & 49.5 & 48.8 & \\
\hline Mean wealth index quintile score & & & & 0.53 & & & & \\
\hline Low & 58.9 & 60.7 & 59.8 & & 44.6 & 45.7 & 45.2 & 0.13 \\
\hline High & 41.1 & 39.3 & 40.2 & & 55.4 & 54.3 & 54.8 & \\
\hline Number of children (N: weighted) & 4677 & 4880 & 9557 & & 13339 & 13801 & 27141 & \\
\hline
\end{tabular}


Appendix Table 3 (cont'd).

\begin{tabular}{|c|c|c|c|c|c|c|c|c|}
\hline \multirow[t]{2}{*}{ Variables } & \multirow{2}{*}{$\begin{array}{c}\text { Rwanda } \\
\text { Female } \\
(\%)\end{array}$} & \multicolumn{7}{|c|}{ Senegal } \\
\hline & & $\begin{array}{c}\text { Male } \\
(\%) \\
\end{array}$ & $\begin{array}{c}\text { Total } \\
(\%)\end{array}$ & p-values & $\begin{array}{c}\text { Female } \\
(\%)\end{array}$ & $\begin{array}{c}\text { Male } \\
(\%)\end{array}$ & $\begin{array}{c}\text { Total } \\
(\%)\end{array}$ & p-values \\
\hline Child size at birth & & & & $<0.001$ & & & & $<0.001$ \\
\hline Average or larger than average & 83.0 & 87.9 & 85.5 & & 69.1 & 74.9 & 72.1 & \\
\hline Very small and smaller than average & 17.0 & 12.1 & 14.5 & & 30.9 & 25.1 & 27.9 & \\
\hline Birth order and preceding birth interval & & & & 0.33 & & & & 0.13 \\
\hline First birth & 26.1 & 24.6 & 25.3 & & 23.2 & 23.8 & 23.5 & \\
\hline $2-3$ and $<24$ months & 8.3 & 8.7 & 8.5 & & 7.2 & 6.1 & 6.6 & \\
\hline $2-3$ and $24+$ months & 25.4 & 26.0 & 25.7 & & 26.3 & 28.3 & 27.3 & \\
\hline $4+$ and $<24$ months & 6.8 & 6.2 & 6.5 & & 7.4 & 7.1 & 7.2 & \\
\hline $4+$ and $24+$ months & 33.5 & 34.6 & 34.0 & & 36.0 & 34.8 & 35.4 & \\
\hline Mother's age at child birth & & & & 0.42 & & & & 0.27 \\
\hline Less than 20 years & 6.5 & 5.9 & 6.2 & & 14.9 & 15.6 & 15.3 & \\
\hline $20-34$ years & 75.2 & 76.3 & 75.8 & & 71.1 & 69.7 & 70.4 & \\
\hline Greater than 35 years & 18.3 & 17.7 & 18.0 & & 14.0 & 14.6 & 14.3 & \\
\hline Skilled attendant at delivery & & & & 0.21 & & & & 0.42 \\
\hline Other (incl. none) & 32.0 & 30.5 & 31.2 & & 41.7 & 42.4 & 42.1 & \\
\hline Doctor, nurse, or midwife & 68.0 & 69.5 & 68.8 & & 58.3 & 57.6 & 57.9 & \\
\hline Type of gender preference & & & & $<0.001$ & & & & $<0.001$ \\
\hline No gender preference & 28.1 & 27.6 & 27.8 & & 28.7 & 27.5 & 28.1 & \\
\hline Balance preference & 39.6 & 38.4 & 39.0 & & 30.4 & 28.1 & 29.2 & \\
\hline Daughter preference & 13.5 & 8.3 & 10.8 & & 6.7 & 3.9 & 5.3 & \\
\hline Son preference & 18.9 & 25.7 & 22.3 & & 34.2 & 40.6 & 37.5 & \\
\hline Maternal education & & & & 0.67 & & & & 0.34 \\
\hline No education & 18.9 & 19.2 & 19.0 & & 70.8 & 71.0 & 70.9 & \\
\hline Primary & 72.6 & 71.8 & 72.2 & & 20.8 & 20.6 & 20.7 & \\
\hline Secondary or higher & 8.5 & 9.0 & 8.8 & & 8.3 & 8.4 & 8.4 & \\
\hline Household wealth Index & & & & 0.36 & & & & 0.12 \\
\hline 1st quintile (Poorest) & 23.7 & 22.9 & 23.3 & & 23.3 & 23.2 & 23.2 & \\
\hline 2nd quintile & 21.4 & 21.9 & 21.7 & & 21.1 & 22.8 & 22.0 & \\
\hline 3rd quintile & 20.1 & 19.6 & 19.8 & & 19.3 & 19.3 & 19.3 & \\
\hline 4th quintile & 18.9 & 18.0 & 18.4 & & 19.9 & 19.2 & 19.5 & \\
\hline 5th quintile (Richest) & 16.0 & 17.5 & 16.7 & & 16.5 & 15.5 & 16.0 & \\
\hline Urban-rural area of residence & & & & 0.062 & & & & 0.43 \\
\hline Rural & 88.7 & 87.3 & 88.0 & & 61.3 & 61.9 & 61.6 & \\
\hline Urban & 11.3 & 12.7 & 12.0 & & 38.7 & 38.1 & 38.4 & \\
\hline Women with secondary or higher (\%) & & & & 0.82 & & & & 0.59 \\
\hline Low & 51.1 & 51.2 & 51.2 & & 43.7 & 43.8 & 43.8 & \\
\hline High & 48.9 & 48.8 & 48.8 & & 56.3 & 56.2 & 56.2 & \\
\hline Women birthing in a health facility (\%) & & & & 0.36 & & & & 0.68 \\
\hline Low & 52.0 & 50.8 & 51.3 & & 38.9 & 39.6 & 39.2 & \\
\hline High & 48.0 & 49.2 & 48.7 & & 61.1 & 60.4 & 60.8 & \\
\hline Women who have a son preference $(\%)$ & & & & 0.24 & & & & 0.27 \\
\hline Low & 50.7 & 49.4 & 50.0 & & 50.6 & 49.1 & 49.8 & \\
\hline High & 49.3 & 50.6 & 50.0 & & 49.4 & 50.9 & 50.2 & \\
\hline Mean wealth index quintile score & & & & 0.016 & & & & 0.86 \\
\hline Low & 52.0 & 49.3 & 50.6 & & 38.8 & 39.1 & 38.9 & \\
\hline High & 48.0 & 50.7 & 49.4 & & 61.2 & 60.9 & 61.1 & \\
\hline Number of children (N: weighted) & 4354 & 4514 & 8868 & & 5364 & 5650 & 11014 & \\
\hline
\end{tabular}


Appendix Table 3 (cont'd).

\begin{tabular}{|c|c|c|c|c|c|c|c|c|}
\hline \multirow[t]{2}{*}{ Variables } & \multicolumn{2}{|c|}{ Sierra Leone } & \multicolumn{6}{|c|}{ Swaziland } \\
\hline & $\begin{array}{c}\text { Female } \\
(\%)\end{array}$ & $\begin{array}{c}\text { Male } \\
(\%)\end{array}$ & $\begin{array}{c}\text { Total } \\
(\%)\end{array}$ & p-values & $\begin{array}{c}\text { Female } \\
(\%)\end{array}$ & $\begin{array}{l}\text { Male } \\
(\%)\end{array}$ & $\begin{array}{c}\text { Total } \\
(\%)\end{array}$ & p-values \\
\hline Child size at birth & & & & $<0.001$ & & & & 0.002 \\
\hline Average or larger than average & 78.2 & 81.5 & 79.8 & & 84.1 & 88.3 & 86.3 & \\
\hline Very small and smaller than average & 21.8 & 18.5 & 20.2 & & 15.9 & 11.7 & 13.7 & \\
\hline Birth order and preceding birth interval & & & & 0.50 & & & & 0.69 \\
\hline First birth & 19.9 & 20.5 & 20.2 & & 33.3 & 30.8 & 32.0 & \\
\hline $2-3$ and $<24$ months & 5.7 & 7.0 & 6.3 & & 5.5 & 6.1 & 5.8 & \\
\hline $2-3$ and $24+$ months & 31.2 & 30.7 & 31.0 & & 31.5 & 33.3 & 32.4 & \\
\hline $4+$ and $<24$ months & 8.0 & 7.6 & 7.8 & & 4.7 & 5.3 & 5.0 & \\
\hline $4+$ and $24+$ months & 35.2 & 34.1 & 34.7 & & 25.1 & 24.5 & 24.8 & \\
\hline Mother's age at child birth & & & & 0.30 & & & & 0.76 \\
\hline Less than 20 years & 16.0 & 17.8 & 16.9 & & 24.4 & 23.1 & 23.7 & \\
\hline $20-34$ years & 69.9 & 67.8 & 68.8 & & 64.3 & 66.1 & 65.2 & \\
\hline Greater than 35 years & 14.1 & 14.4 & 14.2 & & 11.4 & 10.8 & 11.1 & \\
\hline Skilled attendant at delivery & & & & 0.30 & & & & 0.36 \\
\hline Other (incl. none) & 69.4 & 68.1 & 68.8 & & 30.6 & 31.5 & 31.1 & \\
\hline Doctor, nurse, or midwife & 30.6 & 31.9 & 31.2 & & 69.4 & 68.5 & 68.9 & \\
\hline Type of gender preference & & & & $<0.001$ & & & & $<0.001$ \\
\hline No gender preference & 17.8 & 15.0 & 16.4 & & 13.2 & 13.2 & 13.2 & \\
\hline Balance preference & 50.8 & 52.7 & 51.8 & & 51.7 & 51.4 & 51.5 & \\
\hline Daughter preference & 18.2 & 14.5 & 16.4 & & 17.2 & 11.2 & 14.2 & \\
\hline Son preference & 13.2 & 17.8 & 15.5 & & 18.0 & 24.3 & 21.1 & \\
\hline Maternal education & & & & 0.40 & & & & 0.68 \\
\hline No education & 76.7 & 76.3 & 76.5 & & 8.9 & 9.3 & 9.1 & \\
\hline Primary & 12.7 & 11.6 & 12.2 & & 35.7 & 34.2 & 35.0 & \\
\hline Secondary or higher & 10.6 & 12.0 & 11.3 & & 55.4 & 56.5 & 55.9 & \\
\hline Household wealth Index & & & & 0.26 & & & & 0.036 \\
\hline 1st quintile (Poorest) & 21.9 & 23.7 & 22.8 & & 18.8 & 21.9 & 20.4 & \\
\hline 2nd quintile & 22.5 & 19.9 & 21.2 & & 20.5 & 21.3 & 20.9 & \\
\hline 3rd quintile & 22.4 & 21.5 & 22.0 & & 19.5 & 19.9 & 19.7 & \\
\hline 4th quintile & 18.1 & 19.7 & 18.9 & & 21.0 & 17.7 & 19.3 & \\
\hline 5th quintile (Richest) & 15.1 & 15.1 & 15.1 & & 20.2 & 19.1 & 19.6 & \\
\hline Urban-rural area of residence & & & & 0.15 & & & & 0.38 \\
\hline Rural & 73.7 & 72.0 & 72.8 & & 76.9 & 78.4 & 77.7 & \\
\hline Urban & 26.3 & 28.0 & 27.2 & & 23.1 & 21.6 & 22.3 & \\
\hline Women with secondary or higher (\%) & & & & 0.11 & & & & 0.40 \\
\hline Low & 59.1 & 57.5 & 58.3 & & 50.2 & 48.4 & 49.3 & \\
\hline High & 40.9 & 42.5 & 41.7 & & 49.8 & 51.6 & 50.7 & \\
\hline Women birthing in a health facility (\%) & & & & 0.043 & & & & 0.91 \\
\hline Low & 56.7 & 53.4 & 55.1 & & 49.0 & 48.9 & 49.0 & \\
\hline High & 43.3 & 46.6 & 44.9 & & 51.0 & 51.1 & 51.0 & \\
\hline Women who have a son preference $(\%)$ & & & & 0.31 & & & & 0.93 \\
\hline Low & 51.5 & 49.8 & 50.7 & & 55.1 & 55.2 & 55.2 & \\
\hline High & 48.5 & 50.2 & 49.3 & & 44.9 & 44.8 & 44.8 & \\
\hline Mean wealth index quintile score & & & & 0.33 & & & & 0.18 \\
\hline Low & 56.9 & 55.9 & 56.4 & & 49.2 & 52.2 & 50.7 & \\
\hline High & 43.1 & 44.1 & 43.6 & & 50.8 & 47.8 & 49.3 & \\
\hline Number of children (N: weighted) & 2836 & 2764 & 5601 & & 1364 & 1391 & 2755 & \\
\hline
\end{tabular}


Appendix Table 3 (cont'd).

\begin{tabular}{|c|c|c|c|c|c|c|c|c|}
\hline \multirow[t]{2}{*}{ Variables } & \multicolumn{4}{|l|}{ Tanzania } & \multicolumn{4}{|l|}{ Uganda } \\
\hline & $\begin{array}{c}\text { Female } \\
(\%)\end{array}$ & $\begin{array}{c}\text { Male } \\
(\%)\end{array}$ & $\begin{array}{c}\text { Total } \\
(\%)\end{array}$ & p-values & $\begin{array}{c}\text { Female } \\
(\%)\end{array}$ & $\begin{array}{c}\text { Male } \\
(\%)\end{array}$ & $\begin{array}{c}\text { Total } \\
(\%)\end{array}$ & p-values \\
\hline Child size at birth & & & & 0.11 & & & & $<0.001$ \\
\hline Average or larger than average & 91.6 & 92.8 & 92.2 & & 76.4 & 82.4 & 79.4 & \\
\hline Very small and smaller than average & 8.4 & 7.2 & 7.8 & & 23.6 & 17.6 & 20.6 & \\
\hline Birth order and preceding birth interval & & & & 0.098 & & & & 0.45 \\
\hline First birth & 19.9 & 22.2 & 21.0 & & 18.6 & 17.4 & 18.0 & \\
\hline $2-3$ and $<24$ months & 5.5 & 5.5 & 5.5 & & 8.4 & 8.3 & 8.4 & \\
\hline $2-3$ and $24+$ months & 31.3 & 28.5 & 29.9 & & 22.0 & 24.1 & 23.1 & \\
\hline $4+$ and $<24$ months & 7.0 & 6.5 & 6.7 & & 12.7 & 12.7 & 12.7 & \\
\hline $4+$ and $24+$ months & 36.2 & 37.4 & 36.8 & & 38.2 & 37.4 & 37.8 & \\
\hline Mother's age at child birth & & & & 0.18 & & & & 0.27 \\
\hline Less than 20 years & 15.2 & 16.8 & 16.0 & & 17.1 & 16.7 & 16.9 & \\
\hline 20-34 years & 69.4 & 69.4 & 69.4 & & 68.1 & 71.1 & 69.6 & \\
\hline Greater than 35 years & 15.4 & 13.8 & 14.6 & & 14.8 & 12.3 & 13.5 & \\
\hline Skilled attendant at delivery & & & & 0.014 & & & & 1.00 \\
\hline Other (incl. none) & 53.7 & 51.2 & 52.4 & & 42.9 & 42.7 & 42.8 & \\
\hline Doctor, nurse, or midwife & 46.3 & 48.8 & 47.6 & & 57.1 & 57.3 & 57.2 & \\
\hline Type of gender preference & & & & $<0.001$ & & & & $<0.001$ \\
\hline No gender preference & 25.2 & 24.9 & 25.1 & & 17.0 & 16.8 & 16.9 & \\
\hline Balance preference & 42.4 & 44.1 & 43.3 & & 54.3 & 57.1 & 55.7 & \\
\hline Daughter preference & 18.8 & 12.4 & 15.6 & & 19.5 & 13.8 & 16.7 & \\
\hline Son preference & 13.6 & 18.5 & 16.1 & & 9.2 & 12.2 & 10.7 & \\
\hline Maternal education & & & & 0.046 & & & & 0.72 \\
\hline No education & 26.8 & 24.8 & 25.8 & & 14.8 & 13.9 & 14.3 & \\
\hline Primary & 67.1 & 68.7 & 67.9 & & 64.0 & 64.1 & 64.1 & \\
\hline Secondary or higher & 6.1 & 6.6 & 6.3 & & 21.2 & 22.0 & 21.6 & \\
\hline Household wealth Index & & & & 0.68 & & & & 0.76 \\
\hline 1st quintile (Poorest) & 21.8 & 20.4 & 21.1 & & 22.8 & 22.2 & 22.5 & \\
\hline 2nd quintile & 23.9 & 23.4 & 23.7 & & 21.2 & 21.9 & 21.6 & \\
\hline 3rd quintile & 21.9 & 23.0 & 22.4 & & 20.7 & 19.3 & 20.0 & \\
\hline 4th quintile & 18.7 & 18.7 & 18.7 & & 17.7 & 17.5 & 17.6 & \\
\hline 5th quintile (Richest) & 13.7 & 14.5 & 14.1 & & 17.5 & 19.1 & 18.3 & \\
\hline Urban-rural area of residence & & & & 0.34 & & & & 0.59 \\
\hline Rural & 79.3 & 80.1 & 79.7 & & 86.0 & 86.0 & 86.0 & \\
\hline Urban & 20.7 & 19.9 & 20.3 & & 14.0 & 14.0 & 14.0 & \\
\hline Women with secondary or higher (\%) & & & & 0.45 & & & & 0.31 \\
\hline Low & 61.0 & 59.9 & 60.5 & & 52.1 & 50.5 & 51.3 & \\
\hline High & 39.0 & 40.1 & 39.5 & & 47.9 & 49.5 & 48.7 & \\
\hline Women birthing in a health facility (\%) & & & & 0.84 & & & & 0.30 \\
\hline Low & 48.5 & 49.0 & 48.8 & & 54.5 & 53.7 & 54.1 & \\
\hline High & 51.5 & 51.0 & 51.2 & & 45.5 & 46.3 & 45.9 & \\
\hline Women who have a son preference (\%) & & & & 0.005 & & & & 0.50 \\
\hline Low & 57.8 & 55.8 & 56.8 & & 50.5 & 51.1 & 50.8 & \\
\hline High & 42.2 & 44.2 & 43.2 & & 49.5 & 48.9 & 49.2 & \\
\hline Mean wealth index quintile score & & & & 0.066 & & & & 0.64 \\
\hline Low & 55.6 & 54.1 & 54.9 & & 50.7 & 48.9 & 49.8 & \\
\hline High & 44.4 & 45.9 & 45.1 & & 49.3 & 51.1 & 50.2 & \\
\hline Number of children (N: weighted) & 3978 & 3961 & 7939 & & 3892 & 3920 & 7813 & \\
\hline
\end{tabular}




\section{Appendix Table 3 (cont'd).}

\begin{tabular}{|c|c|c|c|c|c|c|c|c|}
\hline \multirow[t]{2}{*}{ Variables } & \multicolumn{4}{|l|}{ Zambia } & \multicolumn{3}{|c|}{ Zimbabwe } & \multirow[b]{2}{*}{ p-values } \\
\hline & $\begin{array}{c}\text { Female } \\
(\%)\end{array}$ & $\begin{array}{l}\text { Male } \\
(\%)\end{array}$ & $\begin{array}{c}\text { Total } \\
(\%)\end{array}$ & p-values & $\begin{array}{c}\text { Female } \\
(\%)\end{array}$ & $\begin{array}{c}\text { Male } \\
(\%)\end{array}$ & $\begin{array}{c}\text { Total } \\
(\%)\end{array}$ & \\
\hline Child size at birth & & & & $<0.001$ & & & & $<0.001$ \\
\hline Average or larger than average & 88.3 & 90.9 & 89.6 & & 86.9 & 89.7 & 88.3 & \\
\hline Very small and smaller than average & 11.7 & 9.1 & 10.4 & & 13.1 & 10.3 & 11.7 & \\
\hline Birth order and preceding birth interval & & & & 0.40 & & & & 0.49 \\
\hline First birth & 19.7 & 21.0 & 20.3 & & 33.1 & 32.4 & 32.8 & \\
\hline $2-3$ and $<24$ months & 5.8 & 5.2 & 5.5 & & 3.6 & 4.0 & 3.8 & \\
\hline $2-3$ and $24+$ months & 30.1 & 28.7 & 29.4 & & 40.8 & 41.2 & 41.0 & \\
\hline $4+$ and $<24$ months & 6.5 & 6.7 & 6.6 & & 2.3 & 1.9 & 2.1 & \\
\hline $4+$ and $24+$ months & 38.0 & 38.4 & 38.2 & & 20.1 & 20.5 & 20.3 & \\
\hline Mother's age at child birth & & & & 0.85 & & & & 0.47 \\
\hline Less than 20 years & 17.4 & 17.7 & 17.6 & & 19.2 & 20.5 & 19.9 & \\
\hline 20-34 years & 69.4 & 69.3 & 69.4 & & 71.8 & 70.4 & 71.1 & \\
\hline Greater than 35 years & 13.1 & 13.0 & 13.1 & & 9.1 & 9.1 & 9.1 & \\
\hline Skilled attendant at delivery & & & & 0.33 & & & & 0.76 \\
\hline Other (incl. none) & 55.7 & 53.8 & 54.7 & & 64.4 & 65.2 & 64.8 & \\
\hline Doctor, nurse, or midwife & 44.3 & 46.2 & 45.3 & & 35.6 & 34.8 & 35.2 & \\
\hline Type of gender preference & & & & $<0.001$ & & & & $<0.001$ \\
\hline No gender preference & 27.0 & 25.4 & 26.2 & & 17.8 & 18.2 & 18.0 & \\
\hline Balance preference & 40.2 & 41.2 & 40.7 & & 49.4 & 49.3 & 49.4 & \\
\hline Daughter preference & 23.1 & 16.2 & 19.7 & & 19.3 & 13.4 & 16.4 & \\
\hline Son preference & 9.8 & 17.2 & 13.5 & & 13.4 & 19.1 & 16.3 & \\
\hline Maternal education & & & & 0.69 & & & & 0.24 \\
\hline No education & 14.4 & 13.0 & 13.7 & & 1.8 & 1.6 & 1.7 & \\
\hline Primary & 62.7 & 63.9 & 63.3 & & 32.7 & 31.5 & 32.1 & \\
\hline Secondary or higher & 22.9 & 23.1 & 23.0 & & 65.6 & 66.9 & 66.2 & \\
\hline Household wealth Index & & & & 0.70 & & & & 0.60 \\
\hline 1st quintile (Poorest) & 23.8 & 23.3 & 23.5 & & 23.1 & 22.7 & 22.9 & \\
\hline 2nd quintile & 23.0 & 22.4 & 22.7 & & 21.1 & 20.8 & 21.0 & \\
\hline 3rd quintile & 21.2 & 20.6 & 20.9 & & 19.8 & 18.9 & 19.3 & \\
\hline 4th quintile & 19.0 & 19.7 & 19.3 & & 20.3 & 22.1 & 21.2 & \\
\hline 5th quintile (Richest) & 13.0 & 14.1 & 13.6 & & 15.7 & 15.6 & 15.6 & \\
\hline Urban-rural area of residence & & & & 0.064 & & & & 0.36 \\
\hline Rural & 72.1 & 69.6 & 70.8 & & 70.5 & 70.0 & 70.3 & \\
\hline Urban & 27.9 & 30.4 & 29.2 & & 29.5 & 30.0 & 29.7 & \\
\hline Women with secondary or higher $(\%)$ & & & & 0.51 & & & & 0.87 \\
\hline Low & 53.7 & 52.8 & 53.2 & & 49.9 & 50.5 & 50.2 & \\
\hline High & 46.3 & 47.2 & 46.8 & & 50.1 & 49.5 & 49.8 & \\
\hline Women birthing in a health facility $(\%)$ & & & & 0.17 & & & & 0.031 \\
\hline Low & 54.5 & 52.3 & 53.4 & & 50.0 & 47.7 & 48.9 & \\
\hline High & 45.5 & 47.7 & 46.6 & & 50.0 & 52.3 & 51.1 & \\
\hline Women who have a son preference $(\%)$ & & & & 0.49 & & & & 0.003 \\
\hline Low & 50.4 & 49.3 & 49.8 & & 52.9 & 48.8 & 50.8 & \\
\hline High & 49.6 & 50.7 & 50.2 & & 47.1 & 51.2 & 49.2 & \\
\hline Mean wealth index quintile score & & & & 0.079 & & & & 0.30 \\
\hline Low & 55.8 & 53.4 & 54.6 & & 48.2 & 47.8 & 48.0 & \\
\hline High & 44.2 & 46.6 & 45.4 & & 51.8 & 52.2 & 52.0 & \\
\hline Number of children (N: weighted) & 3090 & 3066 & 6156 & & 2697 & 2747 & 5444 & \\
\hline
\end{tabular}

